\title{
Cultural Effects on Organizational Resilience: Evidence from the NAFTA Region
}

\author{
Bernhard Fietz $\cdot$ Julia Hillmann $\cdot$ Edeltraud Guenther
}

Received: 23 January 2021 / Accepted: 29 January 2021 / Published online: 19 February 2021

(C) The Author(s) 2021

\begin{abstract}
The purpose of this paper is to investigate the influence of national culture on organizational resilience, the effects of which are analyzed for companies from the North American Free Trade Agreement (NAFTA) region. This paper utilizes an etic approach to study this relationship and has an empirical design with a sample of $N=464$. The direct effect of national culture on organizational resilience is investigated. To measure national culture, this paper relies on the dimensions of Hofstede. A multiple regression analysis is applied to answer the hypotheses. Results show that the dimensions of power distance, individualism, uncertainty avoidance, and indulgence have a significant direct effect on an organization's resilience. This paper confirms the necessity for reflecting upon the importance of national cultures to globally-working organizations. Organizations that are dedicated to proactive development in their organizational resilience must understand the cultural circumstances that might hinder resilience development. Indeed, cultural influences play a significant role in human resource trainings, choices of location, leadership styles, and managing stakeholders and external alliances to improve organizational resilience.
\end{abstract}

\footnotetext{
The data we use was collected in 2006 within a broad survey carried out by the American Management Association, in cooperation with the Human Resource Institute. A subset of that study was used for the publication of Joseph E. McCann, John W. Selsky, and James M. Lee (2009). The authors provided us with this data set for further analysis.

B. Fietz · J. Hillmann

Faculty of Business and Economics/Chair of Sustainability Management and Environmental Accounting, Technische Universität Dresden, Dresden, Germany

\section{E. Guenther $(\bowtie)$}

Institute for Integrated Management of Material Fluxes and of Resources (UNU-FLORES), Center for Sustainability Assessment and Policy PRISMA, Faculty of Business and Economics/Chair of Sustainability Management and Environmental Accounting, United Nations University, 01062 Dresden, Germany

E-Mail: ema@mailbox.tu-dresden.de
} 
This paper is the first to quantitatively study the relationship of national culture on organizational resilience.

Keywords Organizational Resilience $\cdot$ National culture $\cdot$ Hofstede $\cdot$ Cross-country comparison $\cdot$ Survey $\cdot$ NAFTA

JEL Classification M10 - M16 · M59 $\cdot$ Z19

\section{Introduction}

In the decade spanning 1988 to 1998, Korean Air suffered an airplane accident loss rate 17 times higher than that of its safest competitor, United Airlines. The National Transportation Safety Board (NTSB) carried out a thorough and in-depth investigation to identify the reasons behind this development and to address the safety issues of Korean Air. Analysts from the NTSB transcribed the last few minutes prior to the individual accidents and their findings were as surprising as they were simple, with the attributing factor being to national culture (Gladwell 2011). The major reason was found to be mitigated speech (i.e., the downplaying or sugarcoating of what is being said), which is common in cultures with a high power distance index and high context culture (Helmreich and Foushee 1993; Helmreich et al. 2001; Merritt 2000). This was especially problematic in emergency situations, where direct speech was an imperative (Helmreich et al. 2001). Following these results, combating mitigation was introduced as one of the most essential trainings for air crews, with crew members being specifically trained in clear and assertive communication (Helmreich et al. 2001; Merritt 2000).

Certainly, the impacts of culture are not always as alarming as in this example; nevertheless, it demonstrates the importance of national culture. In the context of an organization, national culture can both influence and cause differences in organizational structures and practices (Aycan 2000; Bartlett and Ghoshal 2003; Chiaburu et al. 2015). The value orientation theory (Kluckhohn and Strodtbeck 1961) tells us that cultural phenomena such as norms, values, and beliefs can be categorized into certain cultural dimensions, due to every culture addressing the same underlying problems, such as social coexistence, time and nature. It further emphasizes that every culture — both past and present_faces the same underlying problems and challenges (Hofstede 1993), therefore, necessitating the need for resilience. Due to differences in scores within the distinct cultural dimensions (Hofstede 2001; House et al. 2004), the methods of solving these problems and meeting these challenges — such as achieving resilience-will vary.

Recently, the concept of resilience received considerably higher attention in business and management, which aims to determine how organizations survive and thrive amidst adversity (see reviews of Hillmann 2020; Duchek 2020; Linnenluecke 2017). Organizational resilience is a set of organizational capabilities through which firms anticipate trends and threats, make sense of — and cope effectively with — unexpected events, and adapt to changes to produce a dynamic capability to facilitate organizational change (Duchek 2020; Hillmann et al. 2018; Limnios et al. 2014). A recent 
conceptualization of resilience in the organizational context by Williams et al. (2017) shows the necessary capabilities and endowments that give substance to organizational resilience. ${ }^{1}$ Resilience building and activation requires a social process (Tasic et al. 2019; Williams et al. 2017; Lengnick-Hall and Beck 2005), as it is enacted by individuals and groups in an organization (Chewning et al. 2013; Cho et al. 2006; Horne and Orr 1998; Salanova et al. 2012). For example, resilience involves relational mechanisms that are about the connections of individuals and groups, and the way they collaborate to activate resources and capabilities (Lengnick-Hall and Beck 2005) to respond to adversity.

Organizational phenomena-such as resilience-are impacted by, and depend upon, the context. As no managerial approach or management tool is universally applicable to every situation, decision-makers have to be aware of context-dependencies (Johns 2006, 2018) such as national culture. A case study by Low Kim Cheng (2007) highlights that the resilience in Singaporean companies is shaped by their national culture. The author refers to the Chinese saying, "the ants are busy all the time", to imply that this resilience lies particularly within the Singaporean value of making continuous efforts to grow (Low Kim Cheng 2007). These findings provide avenues for further study of the context-dependent nature of organizational resilience. Other studies have argued that national culture influences shared mission and value (Acar and Winfrey 1994; Wright et al. 2009), which is an important factor of organizational resilience (e.g., Ishak and Williams 2018; McCann et al. 2009). Other studies perpetuate that national culture influences ecological resilience as it emphasizes the value of environment (King 1995) and local ecological knowledge (Whiteman and Cooper 2011).

The way in which resilience mechanisms and endowments are built is through an organization's individuals and teams; both of which are influenced by national culture. This will be reflected in the resilience capabilities and endowments at the organizational level. Considering that cultural background shapes and influences behavior (Hofstede et al. 2010), both corporate managers and employees have a distinct set of values, norms and beliefs that predetermine their actions, such as decisionmaking, and approaches to problem-solving and crisis reaction (Hofstede 1983). Managers and employees will not accept conditions which are completely contradictory to the beliefs, values, and norms that have been shaped by their national culture. Thus, even a strong organizational culture cannot completely overlap or diminish the influence of national culture on corporate managers and employees (Schein 2001). In this vein, organizational resilience is context-dependent on national culture, as each organization is shaped by the decision-making processes and work routines of its members. Some studies addressed certain aspects of national

\footnotetext{
1 Their conceptualization, similar to Lengnick-Hall and Beck (2005), resonates with social-mechanism based theorizing, which is applied in recent organizational studies to study complex organizational phenomena in highly changing environments (see Scott and Davis 2014). These dimensions include contextual, cognitive, and behavioral mechanisms that explain an organizational phenomenon and are reflected in three resilience dimensions of Lengnick-Hall and Beck (2005): contextual resilience, behavioral resilience, and cognitive resilience. Williams et al. (2017) in their conceptualization apply similar thoughts but provide a more nuanced and process-based presentation of the underlying mechanisms which they call endowments.
} 
culture and their influence on organizational resilience and related organizational phenomena, for example, cultures with a high power distance are less democratic in terms of resource distribution (Chakrabarty 2009). Moreover, collectivism strengthens transformational leadership (Walumbwa and Lawler 2003), and individualistic cultures may encourage innovation (Lažnjak 2011). Additionally, long-term orientated cultures that encourage corporate long-term planning has been shown to strengthen organizational resilience (Sulphey 2020), while traits of both long- and short-term orientation can increase organizational resilience (Andersson et al. 2019).

Therefore, the relationship of national culture and organizational resilience represents a fruitful path for further research that still merits empirical investigation (e.g., Walumbwa and Lawler 2003; Low Kim Cheng 2007; Sulphey 2020). This study asks: Which cultural dimensions affect organizational resilience, and how do they affect it?

To address this research gap and understand the influence of culture on an organization's resilience, this study has relied on an etic approach (Gelfand et al. 2007). The study was carried out in the North American Free Trade Agreement (NAFTA) ${ }^{2}$ region, and has yielded six important contributions. First, we have explained and shown the extent to which organizational resilience is culturally context-dependent; including valuable insights for managing organizational resilience. Second, we have added empirical findings on the culturally context-dependent nature of organizational resilience, which represents a sparse research area. Third, our study has applied the complete validated Hofstede Framework of National Culture to provide holistic empirical insights on both research fields, and can act as a valuable resource for future in-depth research. Fourth, findings have shown that national culture directly affects organizational resilience, which has meaningful theoretical implications. Fifth, we have provided managerial implications, and suggested management tools depending on the context of national culture to foster organizational resilience. Sixth and finally, empirical evidence has been included to expand upon the cultural diversity of the NAFTA region; a finding that can enrich current political discussions in the region.

\section{The Role of National Culture for Developing Resilient Organizations}

One definition of national culture that is used in cultural research and organizations is from Kluckhohn (1951), who defines culture as "patterned ways of thinking, feeling and reacting, acquired and transmitted mainly by symbols, constituting the distinctive achievements of human groups, including their embodiments in artifacts; the essential core of culture consists of traditional (i.e., historically derived and selected) ideas and especially their attached values." This study later led to the values orientation theory, which categorizes cultural phenomena such as norms, values and beliefs into certain cultural dimensions - as every culture must address the same underlying problems related to internal coordination and external adaptation, for

\footnotetext{
2 In July 2020, the new trade agreement United States-Mexico-Canada Agreement (USMCA) replaced NAFTA. For this study, we still refer to NAFTA as the data was collected before 2020 .
} 
example, social coexistence, time, and nature (Kluckhohn and Strodtbeck 1961). This gave rise to the empirical studies of Hofstede.

Culture is further defined as the programming of the mind (Hofstede et al. 2010): not individual but collective, common to people (but not all), not visible and can only be seen in people's behavior (Hofstede and McCrae 2004). Culture is, therefore, something that is shared, adapted, and transmitted across time and generations (Gelfand et al. 2007; Triandis 2004). It is through values, norms, rules, and ways of living that we can learn from prior generations and guide society to solve problems (Gunnestad 2006).

From 1967 to 1979, Hofstede conducted his original empirical study to obtain the scores for his cultural dimensions. He developed his framework by using data from more than 116,000 surveys, which were answered by over 88,000 employees from 72 countries at International Business Machines Corporation (IBM). The respondents were chosen from all different departments and hierarchal positions within the whole firm (Hofstede 2001). Since then, many replication studies have been carried out by other researchers, and by Hofstede himself, with data collected from other firms, organizations, and individuals outside IBM (Søndergaard 1994; Kirkman et al. 2006; Hofstede et al. 2010; Beugelsdijk et al. 2015), which confirmed the validity of Hofstede's results and added two more cultural dimensions (long-term orientation and indulgence) to the original four dimensions (power distance, individualism, masculinity, and uncertainty avoidance) which were developed in the original IBM study.

The use of Hofstede's cultural dimensions is widely discussed in literature and has attracted some criticism. The scores of these dimensions are quantified aggregated values for a country's population. Nevertheless, cultural borders are not necessarily equal to political borders (Baskerville 2003; McSweeney 2002). On the one hand, a country may have a multiethnic population-as is the case with many African countries-resulting in distinct subcultures within a country (Alesina et al. 2003). On the other hand, there are people sharing the same culture but are separated by a political border (Alesina et al. 2016), as in Arab and African countries.

Although Hofstede's aggregated cultural values do not necessarily represent all individuals, the average scores do sufficiently cover the basic characteristics of the represented people (Søndergaard 1994; Hofstede 2001; Beugelsdijk et al. 2015). Hofstede's research results were replicated, validated, and have remained stable for decades (Beugelsdijk et al. 2015; Søndergaard 1994; Cohen 2007; Erez and Gati 2004; Rinne et al. 2012). Moreover, the presumption that the differences between countries are derived by factors other than the national culture, neglects the fact that social systems cannot be sustainably established if they are incompatible with the underlying cultural background. As Schein (2001) states, a society and its individuals will not accept conditions which are completely contradictory to their beliefs, values, and norms. Consequently, Hofstede's approach is a widely-used model in economic research to measure and compare characteristics of national culture and the analysis of its impact on economic subjects and processes. 


\subsection{Organizational Resilience as a Set of Organizational Capabilities}

To meet the challenges arising from turbulent environments, and to generate opportunities, organizations must develop resilience capacity (Hillmann et al. 2018; Lengnick-Hall et al. 2011). However, capturing the concept is challenging, and literature is still divided and inconsistent with the definitions and measurement of organizational resilience (Linnenluecke 2017; Hillmann and Guenther 2020). ${ }^{3}$ Recently, researchers have relied on capability-based theorizing for conceptualizations (Hillmann and Guenther 2020; Duchek 2020; Williams et al. 2017). Resilience goes beyond restoration of organizational functionality, and concerns the advancement of organizational processes and the development of new capabilities (Duchek 2020; Lengnick-Hall et al. 2011). In our study, we also drew upon a capability-based conceptualization, and have defined resilience as a set of organizational capabilities by which firms anticipate trends and threats, make sense of, and cope effectively with adversity, and adapt to changes to produce a dynamic capability that is directed towards facilitating organizational change (Limnios et al. 2014; Duchek 2020; Hillmann et al. 2018). To account for the dynamic perspective of resilience, researchers have added a process-based perspective to resilience (Duchek 2020; Williams et al. 2017) and have described capabilities that relate to before, during, and after times of crises: capabilities for durability, organizing and adjusting, responding to major disturbances, and feedback. They have provided a nuanced method of incorporating organizational, as well as collective and individual levels, and describing related endowments (Williams et al. 2017).

Capabilities for Durability These capabilities include several endowments before a crisis that enable a positive adjustment (Williams et al. 2017), for example, financial endowments, such as slack resources that are built in anticipation of adversity (Carmeli and Markman 2011; Williams et al. 2017). Resilient organizations are more resourceful (McCann et al. 2009), due to their constant investment in the company's resource configuration (Vogus and Sutcliffe 2007); in maintaining awareness and ensuring access to resources in case of crises or emergency and, resources can be quickly deployed to counter them, or even create advantage from them (Heifetz et al. 2009).

The importance of employees and cognitive capability endowments must also be recognized to ensure resilience (Lengnick-Hall et al. 2011). By investing in a deep talent pool, motivated and innovative employees that are committed to change (Nicholls-Nixon 2005; Ortiz-de-Mandojana and Bansal 2016; Shin et al. 2012) with a deep social fabric of goodwill (Lengnick-Hall and Beck 2005; Pal et al. 2014) can be attracted. Resilient organizations are more efficacious (Vogus and Sutcliffe 2007) through a staunch acceptance of reality, a deep belief that life is meaningful,

\footnotetext{
${ }^{3}$ One stream of literature discusses if measuring resilience a priori is possible and that resilience is an outcome and can only be assessed a posteriori (e.g., Ortiz-de-Mandojana and Bansal 2016; Stephenson 2010). Another stream of literature emphasizes that resilience can be proactively shaped and is a developmental process and thus a continuum (e.g., Lengnick-Hall et al. 2011; Sutcliffe and Vogus 2003). Therefore, the term resilient organization in this study is understood as an organization that has a high level of resilience if the characteristics (that are described in this section) are distinct.
} 
and an ability to improvise (Coutu 2002). A strong sense of identity and purpose is another characteristic of a resilient organization, their teams, and employees (Freeman et al. 2004; McCann et al. 2009). Cognitive capability endowments further support the ability to anticipate trends and threats (Williams et al. 2017) and allow for the elimination of as many risks and threats as possible (McCann et al. 2009; Rerup 2001; Somers 2009). These organizations invest in enterprise-wide risk management systems (Starr et al. 2003) and use critical insights in creative and flexible ways (Williams et al. 2017). They build routines that not only reduce complexity, but also allow them to absorb and cope with it (Lengnick-Hall and Beck 2005). These are, for example, scenario planning (Bradfield et al. 2005; MacKay and McKiernan 2010; McCann et al. 2009) and organizational ambidexterity (Chermack et al. 2010; Clement and Rivera 2017). Organizations that put emphasis on anticipating events are more likely to continuously monitor and scan the environment or simulate possible unexpected events (Vogus and Sutcliffe 2007) through which they "combine and deploy knowledge and repertoires of action to resolve the problems at hand" (Williams et al. 2017, p. 744). Cognitive capability endowments further include the ability to quickly assimilate new information and recognize changes in the environment, to make sense of them, and direct attention accordingly (Williams et al. 2017). The ability to make sense of a situation is a critical one, as it precedes problem-solving (Weick 1993) and is essential to avoid failure (Chan 2011; Issel and Narasimha 2007); it helps to translate information about changes in the environment, and to understand specific developments and their influence on the organizations' goals and success (Hamel and Välikangas 2003; Mantere et al. 2012; Weick and Sutcliffe 2007). As the complexity and uncertainty of the environment makes it impossible to anticipate all events, resilience is also about the ability to resist disturbances, recover after adverse situations (e.g., Horne and Orr 1998), or adapt to unexpected events (Lengnick-Hall and Beck 2005). Perceiving crises as an opportunity and cultivating a positive organizational culture supports organizations in "buffering" bad news (French and Holden 2012; Jackson and Dutton 1988), and thus, makes them more resilient. Resilient organizations find creative, prompt responses to minimize the impact of unexpected events (McCann et al. 2009; Weick and Sutcliffe 2007).

Capabilities for durability further include behavioral capability endowments, which include being comfortable with uncertainty (Williams et al. 2017), displaying an openness to change (McCann et al. 2009), and a staunch acceptance of reality where change is needed (Coutu 2002). They further include relational capability endowments that are represented in relationships, i.e., coordinative and cooperative practices, that were essential in overcoming challenges (Gittell et al. 2006; Williams et al. 2017). Trust, and well-established networking relationships as protective factors are an intangible resource endowment that has been shown to be important in recovering quickly from a disaster (Williams and Shepherd 2016; Danes et al. 2009). Maintained relationships and strengthened partnerships provide agility (Sheffi 2005; Starr et al. 2003) or put emphasis on strategic alliances to reduce and spread risk (Pal et al. 2014). 
Organizing and Adjustment This process is aimed at anticipating, preventing, or mitigating potentially negative consequences (Williams et al. 2017). Resilient organizations prepare for adversity by techniques (within managing risks to reduce vulnerability which involves developing networks, coordination techniques (within and between organizations)), and the resilience of individual members (Williams et al. 2017). They manage risk through an enterprise-wide risk assessment and management, invest sufficient attention and resources to manage key external relationships, and continuously reevaluate risky external alliances and partnerships that might lead to greater vulnerability of the organization (Starr et al. 2003; McCann et al. 2009). Furthermore, they continuously destroy barriers that impede the flow of work and resources, or new ideas (Dyer and Singh 1998; Goldman et al. 1994). Restoring includes acting quickly in adverse situations, maintaining operations at acceptable performance levels, and developing contingent responses (Williams et al. 2017). This also includes the ability to act quickly and effectively after taking a big hit (McCann et al. 2009), and taking advantages of opportunities quickly (Hamel and Välikangas 2003; McCann et al. 2009).

Responding to Major Disturbances It includes cognitive, behavioral, and contextual responses in times of adversity. When an organization faces disturbance, individuals must be able to immediately access available resources and make timesensitive decisions (Williams et al. 2017). If this access is not available, correction for adjustment cannot be taken and flexibility erodes increasing vulnerability (Williams et al. 2017; McManus et al. 2008). Therefore, resilient organizations are able to quickly deploy and redeploy resources to support execution, and resources to absorb severe surprise or shock without failing (McCann et al. 2009).

Feedback includes the aspect of prior experiences and learning that alters managers and employees' mental models as they encode new knowledge into organizational routines (Hillmann et al. 2018; Williams et al. 2017). However, Williams et al. (2017) concluded that this may have both advantages and disadvantages for organizational resilience.

\subsection{How Individuals and Teams Influence Organizational Resilience}

Researchers have recently begun investigating the multilevel nature of organizational resilience (e.g., Tasic et al. 2019; Williams et al. 2017; Lengnick-Hall et al. 2011).

Mallak (1998) and Horne and Orr (1998) have already discussed the role of individuals in strengthening organizational resilience. For example, Mallak (1998) argues that organizations can only be as resilient as their employees. Resilient individuals demonstrate great persistence through their high self-efficacy (Schwarzer and Warner 2013) and function well under stress and pressure (Mallak 1998). Coutu (2002) highlights that in a resilient organization, employees have a sense of reality which includes a realistic understanding of the situation. The author argues that plain optimism can lead to denial or ignorance of the situation (Coutu 2002). Furthermore, they see the big picture and, due to their realistic assessment of the situation, have a tolerance for ambiguity that is required in turbulent environments and crises (Mc- 
Cann et al. 2009). A resilient organization has employees that learn from their past mistakes and are open to change, which also involves a continuous willingness to learn and acquire new knowledge from past adversities (Williams et al. 2017; McCann and Selsky 2012). However, Horne and Orr (1998) point out that resilient employees do not always equal a resilient organization. These arguments are elaborated upon by Riolli and Savicki (2003, p. 231) who state that, on the one hand, organizational climate can strengthen individuals and, vice versa, organizations can benefit from its employee's coping styles. On the other hand, a bad organizational climate can undermine an individual's resilience, and a high-pressure task environment can drain individual resources and make them less resilient. Additionally, individuals with antagonistic behavior can weaken the organizational climate, and reduce organizational resilience. In crisis situations, individuals' informal social relations become important as they "build unconventional bridges across organization to supplement unavailable formal connections (Tasic et al. 2019, p. 717)". Employees also play an essential role in anticipating and preparing for crisis situations. When employees observe and (mis)interpret their environment, their responses are enacted through the organizational members that give meaning to them (Weick 1969, 1993; Whiteman and Cooper 2011), depending upon how organizational members' attention is structured by organizational arrangements and information collection practices (Baum and Rowley 2005).

There are even less theoretical considerations for the influence of team resilience on organizational resilience. Although research on resilience at the team level is growing (e.g., Chapman et al. 2020; Morgan et al. 2013; Carmeli et al. 2013), few studies on measuring team resilience exist (e.g., Sharma and Sharma 2016); research on it is still in its infancy (Chapman et al. 2020). In their study on measuring team resilience, Sharma and Sharma (2016, p. 37) define team resilience as the "ability to either flourish under difficult situations, manage and adapt to significant change or stress, or simply recuperate from a negative experience are less likely to come across the potentially detrimental effects of intimidating situations (West et al. 2009)". Morgan et al. (2013) propose that team resilience is a psycho-social process that protects individuals in a group from the negative stressors they collectively encounter. Team resilience involves processes in which team members use individual and collective resources to deal with adversity (Morgan et al. 2013), including a high tolerance for ambiguity and uncertainty, and the ability to function well under pressure and stress. Members of resilient teams are well-integrated into key decision-making processes and are good multi-taskers.

Following Cooper (2013), and comparable to arguments of Mallak (1998), the dynamics of each team member's characteristics of resilience ensure a high level of productivity during turbulent times (Cooper 2013). Thus, resilient teams include members that are open to change, can see the big picture, are able to quickly acquire and apply new skills and knowledge, and have adopted the organization's values and beliefs. In as much as an individual's resilience can positively influence organizational resilience processes (Mallak 1998; Coutu 2002), this link can be assumed to be similar for team-level resilience. Resilient teams can therefore positively influence organizational resilience processes. 
Another important aspect is collective efficacy (Morgan et al. 2013) which includes team members appreciating their collective well-developed problem-solving skills, inventiveness and creativity, their ability to making sense of ambiguous situations, and demonstration of moral and physical courage. Furthermore, Putnam (1995) argues that social capital (i.e., social connections, norms, and trust) supports team members in achieving common goals, which, following Sharma and Sharma (2016), are an important factor in resilient teams. This also includes teams having mentors or coaches, and team members that support and trust each other, and are well connected so that they can quickly change roles and responsibilities. This, in turn, positively influences resilience processes at the organizational level.

\subsection{The Influence of National Culture on Organizational Resilience}

Low Kim Cheng (2007) shows that Singaporean companies are resilient as a result of their cultural background focusing on continuous learning and growth. In a study by Gupta et al. (2010), the 'ubuntu' principle is used to explain the family resilience of indigenous African businesses - this study is a rarity, because although the relationship of organizational culture and organizational resilience often features in studies, only few mention the role of national culture (e.g., Acar and Winfrey 1994; Collis 1991). A national culture is characterized by negotiable and non-negotiable values (Schein 2001), and will have a stronger influence on a person's attitude and behavior than organizational culture, if a non-negotiable national culture value conflicts with an organizational culture value (Schein 2001).

Although research around effects of culture on organizational resilience is sparse, some prior research in psychology has been carried out, which this study draws from. In psychology, resilience is understood through protective factors (Bonanno 2004; Gunnestad 2006; Steinhardt and Dolbier 2008) that determine an individual's resilience. Following Gunnestad (2006), those protective factors include (1) network factors (i.e., how well the individual is embedded within the social group and experiences external support), (2) abilities and skills (i.e., physical and mental strength, emotional stability, communication skills, ability to explain him/herself, understand others, or solve problems), and (3) meanings, values, and faith (i.e., existential support from self-understanding, values, attitudes, and faith). Culture influences those protective factors, for example, in the way people from that culture perceive and value networks and engage in them or the skills that are valued. Resilience is explicitly linked to the factor of meaning and values, due to the deeply ingrained cultural influences that drive thought and behavior. Cultural practices can make people less resilient, and can simultaneously act as a resource for resilience (Gunnestad 2006).

Considering the aforementioned aspects of resilience, the influence of national culture on organizational resilience can also be explained through the connection between specific cultural values, norms, and belief systems. Organizational resilience is about organizational capabilities and resources that are, most importantly, enacted by individuals and groups in an organization (Chewning et al. 2013; Cho et al. 2006; Horne and Orr 1998; Salanova et al. 2012), which enhances the need to study cultural effects. Hofstede's dimensions of national culture and their subsequent influences are expanded upon in the following section. 


\section{Hypotheses}

\subsection{Power Distance and Organizational Resilience}

Power distance is defined as "the extent to which the less powerful members of institutions and organizations within a country expect and accept that power is distributed unequally" (Hofstede 2001, p. 98). These inequalities are accepted by both followers and leaders (Tata and Prasad 2015). Power distance influences the hierarchy and structure of an organization, for example whether employees take initiative, or whether they are permitted and willing to participate in decision-making (Euwema et al. 2007; Hofstede 2001; Taras et al. 2010). Subordinates in high power distance cultures that fear expressing disagreement to the boss will be less likely to take initiative. The power distance index (PDI) influences which style of leadership is tolerated or expected by both managers and employees (Tavanti 2012), which in turn affects engagement in decision-making.

Chiaburu et al. (2015) found that PDI influences organizational citizenship behavior, namely, the extent to which employees show engagement and commitment beyond their ordinary tasks. A strong focus on task performance can be particularly observed in employees in countries with a high PDI, as they acknowledge hierarchical order and delegated assignments (Farh et al. 2007). This may enable organizations to fulfill designated tasks and reach organizational goals on target. Conversely, low power distance supports an open relationship between managers and employees, where they are encouraged to engage beyond delegated tasks (Cohen 2007), thereby fostering innovation (Lažnjak 2011). This is important for change processes, and is relevant for organizational resilience, as it is about the general ability of dealing with change, and displaying a fundamental openness to change and acceptance of change (McCann et al. 2009). These processes are dependent upon the power distance relationship between employer and employee (Hergüner and Reeves 2000; Hofstede 2001). A high PDI impairs change processes, as it often manifests in a class system that hinders upward mobility and perpetuates less powerful employees (Markus and Kitayama 1991). As destroying barriers that impede the workflow, resource flow, or ideas (Dyer and Singh 1998; Goldman et al. 1994) is fundamental for a resilient organization, high PDI might be harmful for organizational resilience.

Power distance further influences trust in relationships. High power distance leads to lower trust in external networks compared to low power distance cultures. Low trust in external networks can hinder access to resources (Luczak et al. 2014; Shane 1994) that are essential for dealing with unexpected events. Resilient organizations have well-established support networks and put an emphasis on partnerships and strategic alliances, therefore low trust through high PDI can negatively influence an organization's resilience.

Furthermore, low PDI fosters shared leadership, which strengthens team relations (Hiller et al. 2006). This is achieved through consultation, participation, and cooperation, which are especially valued in low PDI countries (Matveev and Nelson 2004). Gittell et al. (2006) found that positive relationships at work are a prerequisite for organizational resilience, thus, low PDI might be beneficial for organizational resilience. 
Hypothesis 1 (H1) A firm's organizational resilience is negatively associated with the cultural dimension power distance-the higher the PDI score, the lower the organizational resilience.

\subsection{Individualism vs. Collectivism and Organizational Resilience}

Individualism describes the relationship between the individual and the group, that is, how strongly people in a culture derive their own identity from the self or the group (Hofstede 2011; Newman and Nollen 1996; Tata and Prasad 2015). Important characteristics of individualistic cultures are that the members in question are loosely tied to the group (Rinne et al. 2012; Taras et al. 2012; Tata and Prasad 2015), pursue their own interests above those of the group (Luczak et al. 2014; Rinne et al. 2012), emphasize individual initiatives (Tata and Prasad 2015), seize status from accomplishments (Newman and Nollen 1996), and value individual choice and thoughts (Herkenhoff 2004; Tata and Prasad 2015) that may encourage innovation (Lažnjak 2011) and enable flexible reactions to the unforeseen challenges that are beneficial for organizational resilience. As members of individualistic societies are less grouporiented, shared values are less of a priority than in collectivistic cultures (Luczak et al. 2014), which can be detrimental to organizational resilience, considering that shared values and a strong sense of identity and purpose is fundamental to a resilient organization (Freeman et al. 2004; McCann et al. 2009).

Some aspects of collectivistic cultures are beneficial to organizational resilience, and outweigh possible positive effects of individualistic cultures: First, members influenced by collectivistic cultures are loyal to their group, put the interests of their group first, and receive protection from the group at the same time (Hofstede 2001; Newman and Nollen 1996). They are closely connected to their network and have strong ties with other members of their group (Hofstede 2001; Luczak et al. 2010; Rinne et al. 2012), valuing sharing, group goals, and obligations (Jiao et al. 2013; Tata and Prasad 2015). Second, at the team level, collectivism was found to be positively related to collective efficacy and team performance in terms of developing group norms (Celani and Tasa 2010). Those norms include informal rules and expectations that determine the value of group membership and collective responsibility (Celani and Tasa 2010). Third, collectivistic cultures put emphasis on cooperative strategies (Hornsby et al. 2013). For these reasons, a negative relationship of this dimension to organizational resilience is proposed.

Hypothesis 2 (H2) A firm's organizational resilience is negatively associated with the cultural dimension individualism - the higher the IDV score, the lower the organizational resilience.

\subsection{Masculinity vs. Femininity and Organizational Resilience}

The gender dimension of masculinity vs. femininity refers to values beyond absolute gender difference. These values are related to masculine or feminine roles in a society (Hofstede et al. 2010; Tavanti 2012). Masculinity is characterized by values like assertiveness, competition, performance, and focus on material success, 
while feminine values include maintaining relationships, solidarity, service orientation, and quality of life issues (Luczak et al. 2010; Taras et al. 2012; Tavanti 2012). A country scores highly for this dimension when male values are more present in the society than feminine values (Hofstede et al. 2010; Tavanti 2012). Hofstede suggests that feminine societies might be more successful in the service sector, due to their emphasis on social relationships (Hofstede 1983; Luczak et al. 2010). Masculine societies pursue management practices, with a focus on doing and acquiring, rather than thinking and observing. Achievement and avoiding failure are more important than in feminine cultures that encourage affiliation, and treat failure as less decisive (Newman und Nollen 1996).

Furthermore, the dimension of masculinity vs. femininity may have an impact on the relationship between an employee and the organization. When organizations are less supportive of their employees, employees rely more on self-sufficiency in masculine societies than in feminine societies. Employees are shown to be more team-oriented and valued and supported by their employers in feminine cultures (Chiaburu et al. 2015).

Moreover, the gender dimension indicates a tendency towards shared values. Due to their social orientation, feminine cultures encourage shared values, while masculine cultures are more performance-oriented and foster more individual-based results (Luczak et al. 2014).

For this dimension, the relationship to organizational resilience is not clear, as there is no defined expectation for a specific direction. Employees with a predominant feminine cultural background emphasize support and teamwork, which could result in higher organizational resilience, as knowledge-sharing and collective commitment can strengthen an organization and prepare for unpredicted situations. However, the focus on assertiveness, competition, and performance valued in masculine cultures can also be beneficial for organizational resilience, such as in a period of crisis. Therefore, it is assumed that there will be no clear connection between this cultural dimension and organizational resilience.

Hypothesis 3 (H3) A firm's organizational resilience is not associated with the cultural dimension masculinity.

\subsection{Uncertainty Avoidance and Organizational Resilience}

Uncertainty avoidance is defined as the degree to which people react to situations they cannot predict (Hofstede 2001; Taras et al. 2012). It indicates how a culture deals with ambiguity and situational demands. Members of a culture with high uncertainty avoidance wish to avert uncertain situations and feel uncomfortable or even threatened without clear structures or regulations. In cultures with low uncertainty avoidance, people are open to change, more flexible, less formal, and willing to take risks (Doney et al. 1998; Tata and Prasad 2015).

In addressing a society's tolerance for uncertainty and ambiguity, this cultural dimension also refers to the search for truth. Cultures with a high level of uncertainty avoidance are not only trying to reduce the likelihood of uncertain situations by a tight framework of laws, rules, regulations, and security measures, they also tend 
to find a way to deal with ambiguous situations on a philosophical and religious level, for example, through a belief in an absolute truth (Hofstede 2011; Tavanti 2012). Members of high uncertainty avoidance cultures rely on traditional social norms, established administrative practices, and formalized procedures to prevent events which could have a negative impact (Alas et al. 2011). They articulate expectations very clearly (Congden et al. 2009).

On the contrary, members of a culture with low uncertainty avoidance (and thus, a high uncertainty tolerance) are more open-minded towards different opinions and new approaches that may differ from daily routines, and think outside the box (Tavanti 2012) to encourage innovative solutions (Lažnjak 2011). This tendency towards flexible thinking might be beneficial for organizational resilience, as it can aid adaptation to unexpected events and sudden critical situations (Tata and Prasad 2015). In contrast to high uncertainty avoidance cultures, where risks are avoided through the implementation of strict rules, cultures with a low uncertainty avoidance level aim to reduce risks by engaging in long-term relationships (Doney et al. 1998; Luczak et al. 2014). However, these positive traits of low uncertainty avoidance cultures regarding organizational resilience such as pragmatism, readiness for change, and flexibility, are also accompanied by less positive tendencies, such as spontaneity instead of planning and proactivity - thereby being mostly driven by outside influences rather than actively shaping their corporate environment to improve conditions and influence and foster organizational resilience. As high uncertainty avoidance index (UAI) cultures prepare for various situations and outcomes, as well as an uncertain future, by establishing comprehensive frameworks and guidelines, it is assumed that the traits of high uncertainty avoidance outweigh the traits of low uncertainty avoidance and thus, high uncertainty avoidance has a positive impact on organizational resilience.

Hypothesis 4 (H4) A firm's organizational resilience is positively associated with the cultural dimension uncertainty avoidance - the higher the UAI score, the higher organizational resilience.

\subsection{Long-term Orientation and Organizational Resilience}

The cultural dimension of long-term vs. short-term orientation depicts the focus on the future. Cultures with long-term perspectives emphasize long-term relationships and concentrate on the future-valuing persistence, diligence, dedication, and thrift (Hofstede 1993). Long-term orientation has a positive influence on trust, as relationships are expected to last for a long time and are designed to be beneficial for all stakeholders. Furthermore, long-term oriented relationships tend to be on a more personal level than short-term relationships (Luczak et al. 2010). Thus, social sanctions resulting from violations of trust have a much larger impact than in more business-oriented short-term relationships (Chung et al. 2006).

Short-term orientation focuses on the present and, to a certain degree, on past experiences. Relationships are on a transactional level, are more specific, and based upon values like personal stability (Grimmer and Oddy 2007). Short-term oriented 
cultures are more competition-focused, and interested in fast and short-term solutions (Luczak et al. 2010).

Organizations with long-term orientation are seen as being more sustainable. Managers in long-term oriented cultures tend to be more patient, focused on longterm profits-even to the extent of giving up immediate benefits - to ensure the organizations' long-term development. This should be beneficial in the case of organizational resilience, as an investment in organizational resilience may come to fruition over a longer timeframe (Ortiz-de-Mandojana and Bansal 2016). Employee development, community involvement, and environmental protection require longterm oriented engagement, and are more likely to be pursued by managers with a long-term orientation (Tata and Prasad 2015; Newman and Nollen 1996). Moreover, networks built on long-term relationships might enable access to diverse and useful resources. As business partners consider their results to relate to their partners' results, relational exchanges to maximize profits are emphasized (Luczak et al. 2010). Short-term oriented managers focus on transactional exchanges with their business partners, which aim for prompt returns and fast solutions, sometimes even at the expense of possible future benefits (Tata and Prasad 2015). Nevertheless, there are also situations that require immediate action and a focus on short-term return on investments, especially for companies operating in a highly competitive market environment. There is always an uncertainty if, and when long-term actions and investments pay off, therefore a focus on the current situation cannot be neglected. Companies can put themselves in a favorable market position if they can react and adapt quickly to changing market conditions and external influences. Short-term oriented companies tend to pursue more specific transactions with more detailed and elaborated goal-setting (Luczak et al. 2010). Thus, there are also aspects of shortterm orientation that might be beneficial for organizational resilience.

However, as long-term oriented companies are considered to be more sustainable, and might be better prepared for unforeseen events thanks to elaborate long-term scenario planning (Ortiz-de-Mandojana and Bansal 2016), it is assumed that the effects of a long-term orientation will outweigh the effects of a short-term orientation, and thus long-term orientation has a positive effect on organizational resilience.

Hypothesis 5 (H5) A firm's organizational resilience is positively associated with the cultural dimension long-term orientation-the higher the LTO score, the higher the organizational resilience.

\subsection{Indulgence and Organizational Resilience}

The cultural dimension of indulgence vs. restraint describes how people may control their desires, behavior, and emotions (Hofstede et al. 2010). In sum, it depicts the degree to which people value pleasure over duty (Zhou et al. 2015). Indulgent cultures are characterized by a weak control over desires, behavior, and emotions (Hofstede 2011). Hedonistic values and leisure time are very important, with such a society accepting an expressive way of satisfaction and enjoyment of life. People tend to be rather optimistic; value their individual freedom, and live more in the 
moment. They also have a more accepting attitude for spending money to satisfy their needs and desires (Ismail and Lu 2014).

A study from Lažnjak (2011) indicates that societies with a high score on indulgence have a higher innovation rate than restrained societies. A restraint culture maintains strong control over people's desires, feelings, impulses, behavior, and emotions. They are regulated by strict social norms (Gallego-Álvarez and Ortas 2017). Leisure activities are in general less important than the professional life in general, with people displaying more long-term orientation, pursue utilitarian values and are rather pessimistic regarding future outlooks (Zhou et al. 2015).

People from cultures with high indulgence scores create a positive and relaxed working atmosphere that promotes networking and team commitment. Personal and professional satisfaction is more important than routine activities, tangible rewards, and high salaries. In professional life, members of indulgent cultures are intrinsically motivated, as opposed to the extrinsic motivation in restraint cultures (Dumitraşcu and Dumitraşcu 2016).

Nevertheless, people of restraint cultures display higher persistence in their professional lives, as they are determined by duty, and are used to following strict rules and regulations (Hofstede et al. 2010). They are used to working hard and are willing to work overtime if it is required to get the job done. Such a dedicated work ethic among managers and employees might strengthen organizational resilience, and in the event of unforeseen or critical situations, managers and employees will do everything possible to ensure corporate success.

People from restraint cultures are also more likely to accept their vulnerabilities as a consequence of their duties in their professional and private lives. In many cases, they do not even express their concerns, often because of rigid social norms (Upadhyaya and Rittenburg 2015), which may result in a feeling of helplessness.

Indulgent cultures are expected to be less vulnerable, due to the tendency for people to be more optimistic and happier as they choose their own way of life, as opposed to feeling pressured in restraint cultures (Dückers et al. 2015). Furthermore, members of indulgent cultures tend to actively manage and respond to vulnerabilities by participating in programs, expressing themselves to others, and actively looking for help. Managing vulnerabilities is essential for building organizational resilience and organizations can only be as resilient as their individuals (Coutu 2002; Horne and Orr 1998; Mallak 1998), consequently, a high indulgence score should be beneficial.

Hypothesis 6 (H6) A firm's organizational resilience is positively associated with the cultural dimension indulgence-the higher the IVR score, the higher the organizational resilience. 


\section{Methodology}

\subsection{Sample}

The sample is the result of an online survey conducted by the American Management Association and Human Resource Institute in 2006 (AMA 2006). ${ }^{4}$ The study investigated drivers or barriers of organizational change, agility and resiliency, and how higher-performing organizations manage turbulence in different industries (AMA 2006). As Bono and McNamara (2011) point out, cross-sectional data, although not without flaws, can be potentially useful if both the research question and the research design are matched. We argue that the application of cross-sectional data is beneficial in analyzing the effects of national culture, as one major point of critique of Hofstede's first data collection published in 1980 was a lack of cross-sectional data (Baskerville 2003; McSweeney 2002) which may result in measuring the subculture of a particular industry instead of the national culture. Consequently, in his replication studies that resulted in Hofstede's matched 2010 dataset used in our study, cross-sectional data was collected and analyzed to acquire the scores of the six cultural dimensions (Hofstede et al. 2010). The use of cross-sectional data in our case is beneficial in that it allows for the analysis of the effects of national culture on organizational resilience rather than one subculture of a particular industry.

Respondents include senior executives, managers, and high-level human resource professionals responsible for, or intimately involved in, change management initiatives within their organizations (McCann et al. 2009). The applied resilience data and our subsequent analysis refers solely to the branch location in the respective country (USA, Canada, or Mexico) and does not include foreign subsidiaries. 72\% of the participating companies stated that they employ nationals of their country almost exclusively. Twenty eight percent (28\%) of the companies have a higher degree of multinational employees; however, a majority of the employees in the surveyed branch are still nationals of the branch's location. Thus, it is feasible to apply Hofstede's national culture dimensions to the surveyed branches. There are numerous other studies conducting the same approach (Kirkman et al. 2006; Tsui et al. 2007; Ronen and Shenkar 2013).

Furthermore, our data represents old data which can still act as a source for generating valuable insights (Zimmerman 2008). The reasons for using old data are

\footnotetext{
${ }^{4}$ The researchers that collected the data in cooperation with the American Management Association and Human Resource Institute provided us with the dataset to do further analysis. Our sample therefore represents a secondary data set that includes collected data on resilience and agility in organizations. The data was already published in 2009 (see McCann et al. 2009) and included a sample of organizations from the NAFTA region. The applied items to measure resilience at the individual, team, and organizational level are influenced by social mechanism-based theorizing and are later published, in an updated version, in McCann and Selsky (2012). However, at that time, those ideas represented an early understanding of resilience in organizations, and therefore, the items and scale represent an early version of a hypothetical construct. Unfortunately, theoretical considerations about resilience provided by McCann and Selsky have somehow been overlooked within resilience research in the business and management context. The reason for that is that these conceptualizations have not been published in management journals and, thus, can be put in the category of what Crane (1969) calls invisible college. Therefore, the measurement represents an early but theoretically sound resilience scale.
} 
threefold: First, there are no quantitative empirical studies on the effects of national culture on organizational resilience to refer to. There are two qualitative studies by Low Kim Cheng (2007) and Gupta et al. (2010). In the event of new research field development, it is, following Zimmerman (2008), feasible to draw new knowledge from old data to open a new avenue for further research. In a letter from the Editor, Stolowy (2017) qualifies old data as acceptable "if the work is based on 'private/ specific/original data that date from several years ago' but for which the phenomenon studied is still of current interest (p. 415)". We are convinced that these criteria apply in our case, and as such, we decided to use that rich dataset and matched it with data of Hofstede's national culture framework.

The cultural dimension scores for power distance, uncertainty avoidance, individualism, masculinity, long-term orientation, and indulgence were added to that sample. For this study, the scores published in Hofstede et al. (2010) have been applied, as the Hofstede's data from 2001 provides the scores for the four original dimensions of his framework, and the 2010 data offers scores for the newer dimensions of long-term orientation and indulgence for all three countries of our sample. Validation studies (e.g., Hofstede 2001; Beugelsdijk et al. 2015; Schmitz and Weber 2014) show that national cultures are stable over a longer period of time. By comparing the 1980 publication to the 2001 publication, most of Hofstede's scores have not changed at all, and when there was a changing value, it accounted for only a small margin that did not affect construct validity (Hofstede 2001; Beugelsdijk et al. 2015; Schmitz and Weber 2014). Consequently, it can be reasonably assumed that Hofstede's scores (2001) for the four original dimensions first published in Hofstede (1980) can be matched with the scores of Hofstede et al. (2010) for the newer dimensions of long-term orientation and indulgence for all three countries of our sample. This matched Hofstede et al. framework (2010) was also validated by replication studies (Schmitz and Weber 2014). Thus, the two different times of data collection and publication of the cultural dimensions were not deemed critical for the application and analysis in our study. Moreover, a new comprehensive cultural framework comparable to Hofstede with newly collected data has not yet been published (Ronen and Shenkar 2013).

\subsection{Dependent Variable}

The resilience of the organization (OrgRes) was measured with 17 items (see McCann et al. 2009; American Management Association (AMA) 2006). These items measure several aspects relevant to organizational resilience (Appendix, Table 4) on a 5-point Likert scale.

\subsection{Independent Variables}

National culture is considered the main predictor variable. To measure national culture, this study has relied upon the cultural dimensions of Hofstede. National culture is measured by the dimensions of power distance index (PDI), individualism vs. collectivism (IDV), uncertainty avoidance index (UAI), masculinity vs. femininity (MAS), long-term orientation vs. short-term normative orientation (LTO), and 
indulgence vs. restraint (IVR) (Hofstede et al. 2010). The archival data provided by Hofstede et al. (2010) is applied.

Although Hofstede is not without criticism (see, for example, Baskerville 2003; McSweeney 2002), there are various reasons to apply Hofstede in empirical studies (Cohen 2007; Livermore and Rippa 2014; Rinne et al. 2012). First, robust factor analyses have shown that Hofstede's work is valid and reliable, and has strong correlations with other cultural indices (Rinne et al. 2012). Erez and Earley (1993) showed that most of the criticism is not valid, and that Hofstede's work is clear and parsimonious. Therefore, secondly, Hofstede's work is considered one of the leading models for the study of cross-cultural differences (Brewer and Venaik 2014; Beugelsdijk et al. 2015); it is also the most-applied measure in studies on culture and organizational phenomena, particularly organizational behavior (Cohen 2007; Erez and Gati 2004; Beugelsdijk et al. 2015). Moreover, the literature examining the relationship between (aspects of) organizational resilience and the Globe study, that is the second-highest recognized national culture model in the management context next to Hofstede's dimensions, is sparse.

As we explain in section 2.3, we have assumed that individual and team resilience also influences organizational resilience. We also assumed that those constructs have a stronger influence than national culture. Therefore, we have included the data on both levels to explore and account for their influence. Individual resilience is measured through 17 items (see AMA 2006) on a 5-point Likert scale (see Appendix, Table 4). Team resilience is measured through 18 items on a 5-point Likert scale that measures aspects of team resilience (see AMA 2006).

\subsection{Control Variables}

As another control variable, environmental turbulence was included to see if companies in a turbulent environment are more, or less resilient than companies in a stable environment. This was measured through an overall composite measure that is created by pace of change and disruptiveness (McCann et al. 2009; AMA 2006). Pace of change was measured by the respondents' perception of the current pace of change as experienced over the past five years. They were asked whether the pace is (1) actually slower-briefer periods of significant change, (2) about the same and still predictable, (3) faster but still predictable, (4) much faster and increasingly unpredictable, or (5) extremely fast-it is impossible to predict what will happen next (see McCann et al. 2009). For disruptiveness, respondents were asked to compare the past five years to current experienced conditions: (1) fewer and less frequent shocks and surprises than before, (2) about the same number and frequency of shocks and surprises, (3) more shocks and surprises, (4) many more shocks and surprises, or (5) very many more shocks and surprises (see McCann et al. 2009).

It was further controlled for profitability, as building resilience of an organization is related to costs (Boin and van Eeten 2013) and is more likely to be implemented by organizations with financial resources (Gittell et al. 2006; Ortiz-de-Mandojana and Bansal 2016).

Organizational resilience might vary according to the life cycle stage of an organization. Literature has referred to the problem of rigidity in established organizations 
(e.g., Gilbert 2005; Limnios et al. 2014) being linked to both the failure and survival of organizations (Välikangas 2007). A reasonably well-established company might suffer from rigidity, but can still show resilience-also called undesirable resilience by Limnios et al. (2014). Therefore, we have used the life cycle stage as a control variable. Life cycle stage was measured through the respondents' selfassessment: 1 = Start-up focusing on introducing new products, 2 = rapidly growing firm with increasing market share, $3=$ mature firm with brand name recognition, $4=$ Firm repositioning itself for the future, $5=$ Firm focused on increasing quality and profitability, and $6=$ established firm with strong structure and system. These six categories align with existing literature on organizational life cycle stages and can be related to the stages Birth, Growth, Maturity, Revival, and Decline (see Lester et al. 2003; Miller and Friesen 1984; Quinn and Cameron 1983).

Size as a control variable was further included and was measured in terms of workforce. In the original survey, workforce was measured through five categories (i.e., $1=100-499 ; 2=500-999 ; 3=1000-3499 ; \quad 4=3500-4999 ; 5=5000-9999$; $6=10,000$, and more). These categories are difficult in terms of scale and distant measurement, so they were transformed into three dummy variables to enhance interpretability. Miller and Cardinal (1994) have defined small to medium-sized companies as those with up to 500 employees, and large companies are considered those with over 500 employees. Therefore, the first dummy variable was built for medium-sized companies (100-499). The remaining categories were divided into two further dummy variables: large company (500-4999) and very large company (5000 and more).

In terms of sector related effects, four dummy variables were created that controlled for economic sector affiliations. The dummies included primary, secondary, tertiary, and other sectors (Kenessey 1987). Companies that could not be assigned to a single economic sector were classified in the category "other".

No country controls were added, as findings from prior research indicates that cultural dimensions correlate with country level indicators, such as code of law, corruption, or human rights (Cox et al. 2011; Daniels and Greguras 2014). Many of these country differences occur because the underlying national culture (i.e., beliefs, norms and values) is the dominant factor for the establishment of social structures, such as the legal system (Schein 2001; Hofstede et al. 2010).

\subsection{Missing Values}

Following Karam and Ralston (2016), another step in preparing the analysis was the correction of problems in the data set. Missing data is a problem that all researchers face, but it is usually not explicitly addressed (Cole 2008; Schafer and Graham 2002). Therefore, it is important to think about what to do with missing data, and to clearly describe the techniques for future replication purposes (Karam and Ralston 2016).

There are two types of missing values in the data set. First, some companies did not answer all questions related to a specific level, such as individual or team level. These cases were deleted listwise, as they exceeded the 5\% cut-off level (DiLalla and Dollinger 2006). Second, some responded with "don't know" to some of the 
questions. This category allows the respondent to make a choice if a particular question does not apply for the respondent or if one is not able to answer. Following Ang (2014), these data values should be treated as missing data. How missing data is dealt with depends on various aspects. Many researchers in social science decide to exclude these cases through listwise deletion (Karam and Ralston 2016); however, alternatives to this should be considered, since listwise deletion is not acceptable in some cases, for example, the presence of a pattern behind the lack of information (Lynch 2007; Schafer and Graham 2002; Osborne 2013). If the data is not missing completely at random (MCAR condition), these cases should not simply be eliminated from further consideration (Lynch 2007; Little and Rubin 2002; Osborne 2013). Following Allison (2001) and Osborne (2013), replacing the missing data with MI based on the EM algorithm is acceptable and has advantages over mean substitution. Nevertheless, to ensure that inferences from the results are not influenced by the missing data, a dummy variable can control the applied treatment (Young 2012). We have added a dummy variable into the regression that indicates cases with missing data.

\subsection{Factor Analysis}

Before regression analysis, a factor analysis was applied for the three variables of individual, team, and organizational resilience (Costello and Osborne 2005; Karam and Ralston 2016). First, sample adequacy was tested by calculating the Bartlett's test of sphericity, as well as the Kaiser-Meyer-Olkin (KMO) index (Karam and Ralston 2016). The KMO value was above 0.9, which indicates that the dataset is perfectly suitable for dimension reduction (Kaiser 1974; Yong and Pearce 2013). Bartlett's test of sphericity was also highly significant $(p<0.001)$, therefore factor analysis is appropriate.

Subsequently, a principal-axis factor analysis with an oblique rotation (oblimin) was carried out. Theoretically, a multi-dimensional factor solution and a high correlation of factors were assumed, which deemed an orthogonal rotation inappropriate. Following Costello and Osborne (2005), an uncorrelated factor solution is rather rare, especially in social sciences. Besides, if the factor solution is orthogonal, an oblique rotation would produce the same results as an orthogonal rotation (Costello and Osborne 2005).

All items that strongly violated the commonality, such as cross-loading or factor-loading criteria, were eliminated (e.g., Costello and Osborne 2005). Items with a communality value of less than 0.2 also had to be eliminated (Child 2006). Communalities with 0.4 or higher are good and, for items in the range $0.2-0.4$, research discussions can be based on theory about whether to drop or keep the items (Costello and Osborne 2005). For individual resilience and team resilience, four items had to be excluded. For organizational resilience, two items were excluded. Results surprisingly showed a one-factor solution for individual, team, and organizational resilience (Table 1).

We further tested for common method bias for organizational resilience, team resilience, and individual resilience. Since the data for all items was collected within a single survey and in a cross-sectional manner, the data might underlie a common 
Table 1 Factor analyses results

\begin{tabular}{|c|c|c|c|}
\hline Items & $\begin{array}{l}\text { Cronbach's } \\
\text { alpha }\end{array}$ & $\begin{array}{l}\text { Factor load- } \\
\text { ings }\end{array}$ & $\begin{array}{l}\text { Communali- } \\
\text { ties }\end{array}$ \\
\hline \multicolumn{4}{|l|}{ Organizational resilience } \\
\hline Open to change & 0.95 & 0.70 & 0.49 \\
\hline Actively and widely scans for new information & & 0.76 & 0.57 \\
\hline Good at making sense of ambiguous situations & & 0.79 & 0.62 \\
\hline $\begin{array}{l}\text { Invests sufficient attention and resources to manage } \\
\text { key external relationships }\end{array}$ & & 0.70 & 0.49 \\
\hline Takes advantage of opportunities quickly & & 0.79 & 0.62 \\
\hline $\begin{array}{l}\text { Good at quickly deploying and redeploying re- } \\
\text { sources to support execution }\end{array}$ & & 0.77 & 0.59 \\
\hline $\begin{array}{l}\text { Can absorb a severe surprise or shock without fail- } \\
\text { ing }\end{array}$ & & 0.75 & 0.57 \\
\hline Reacts quickly and effectively after taking a big hit & & 0.77 & 0.59 \\
\hline Strong sense of identity and purpose & & 0.73 & 0.53 \\
\hline $\begin{array}{l}\text { Strong support network of external alliances and } \\
\text { partnerships }\end{array}$ & & 0.70 & 0.50 \\
\hline $\begin{array}{l}\text { Good at enterprise-wide risk assessment and man- } \\
\text { agement }\end{array}$ & & 0.79 & 0.62 \\
\hline Expanding its external alliances and partnerships & & 0.67 & 0.45 \\
\hline Continuously breaks down boundaries and barriers & & 0.80 & 0.64 \\
\hline $\begin{array}{l}\text { Actively reevaluates risky external alliances and } \\
\text { partnerships }\end{array}$ & & 0.67 & 0.45 \\
\hline Clearly defined and widely held values and beliefs & & 0.70 & 0.49 \\
\hline \multicolumn{4}{|l|}{ Team resilience } \\
\hline Open to change & 0.94 & 0.77 & 0.59 \\
\hline High tolerance for ambiguity and uncertainty & & 0.69 & 0.48 \\
\hline Good at making sense out of ambiguous situations & & 0.77 & 0.59 \\
\hline Quickly change roles and responsibilities & & 0.78 & 0.61 \\
\hline Function well during pressure and stress & & 0.75 & 0.56 \\
\hline Well-integrated into key decision-making processes & & 0.71 & 0.51 \\
\hline Good multi-taskers - can do many things at once & & 0.71 & 0.51 \\
\hline See the big picture & & 0.79 & 0.63 \\
\hline $\begin{array}{l}\text { Have great persistence — can demonstrate moral and } \\
\text { physical courage }\end{array}$ & & 0.70 & 0.48 \\
\hline $\begin{array}{l}\text { Quickly acquire and apply new skills and knowl- } \\
\text { edge }\end{array}$ & & 0.81 & 0.65 \\
\hline Well-developed group skills (e.g. problem-solving) & & 0.79 & 0.62 \\
\hline $\begin{array}{l}\text { Have members who mentor, coach, and support } \\
\text { each other }\end{array}$ & & 0.71 & 0.50 \\
\hline Adopted the organization's values and beliefs & & 0.65 & 0.42 \\
\hline Quickly take advantage of situations & & 0.77 & 0.60 \\
\hline Think outside the box-are inventive and creative & & 0.84 & 0.70 \\
\hline
\end{tabular}


Table 1 (Continued)

\begin{tabular}{llll}
\hline Items & $\begin{array}{l}\text { Cronbach's } \\
\text { alpha }\end{array}$ & $\begin{array}{l}\text { Factor load- } \\
\text { ings }\end{array}$ & $\begin{array}{l}\text { Communali- } \\
\text { ties }\end{array}$ \\
\hline $\begin{array}{l}\text { Individual resilience } \\
\text { Open to change }\end{array}$ & 0.93 & 0.71 & 0.50 \\
High tolerance for ambiguity and uncertainty & & 0.57 & 0.33 \\
Can quickly change roles and responsibilities & 0.76 & 0.57 \\
Function well during pressure and stress & & 0.70 & 0.49 \\
Good at making sense of ambiguous situations & 0.74 & 0.55 \\
See the big picture & 0.74 & 0.55 \\
Have great persistence & & 0.72 & 0.51 \\
Quickly take advantage of situations & 0.71 & 0.51 \\
Think outside the box-are inventive and creative & & 0.75 & 0.56 \\
Have strong, positive self-concepts & 0.78 & 0.61 \\
Have adopted the organization's values and beliefs & & 0.55 & 0.31 \\
Are good mentors and coaches & 0.71 & 0.51 \\
Quickly acquire and apply new skills and knowl- & 0.72 & 0.51 \\
edge & & \\
\hline
\end{tabular}

The KMO measure of sampling adequacy was above 0.9; extraction: principal axis factoring; rotation: Oblimin with Kaiser normalization

Reliability-tests: Inter-item correlation in the range all above 0.3; Item-scale statistics is between 0.3-0.7; item deletion would not increase reliability

method bias (Podsakoff et al. 2003). To examine whether common method bias is present, we conducted a Harman's Single Factor test and the common latent factor method. No evidence for common method bias was found.

\subsection{Regression Models}

Within this study, culture is treated as the main effect (Type I hypothesis) (Aycan 2000; Lytle et al. 1995) and, therefore, culture is studied as the independent variable with a direct effect on organizational resilience, resulting in the following regression model:

$$
\begin{aligned}
\text { OrgRes } & =\beta_{0} \\
& +\beta_{1} \text { Culture } \\
& +\beta_{2} \text { TeamRes }+\beta_{3} \text { IndRes } \\
& +\beta_{4} \text { Profitability }+\beta_{5} \text { Turbulence }+\beta_{6} \text { Life cycle stage } \\
&
\end{aligned}
$$

Literature has emphasized that the Hofstede dimensions are correlated (see Baskerville 2003; Schmitz and Weber 2014), as seen with power distance (PDI) being highly correlated with individualism (IDV) (see Dückers et al. 2015). Thus, the correlations of the cultural dimensions in the sample were tested by using a Pearson Correlation Coefficient. Results showed that cultural dimensions were significantly correlated, with $p=0.01$ (two-tailed). Thus, each cultural dimension was entered separately into the regression to eliminate multicollinearity. 
Table 2 Descriptive statistics of all variables included in the regression models

\begin{tabular}{|c|c|c|c|c|c|}
\hline Variable & $N$ & Min & Max & Mean & SD \\
\hline \multicolumn{6}{|l|}{ Dependent variable } \\
\hline OrgRes & 464 & -3.22 & 2.03 & -0.002 & 0.97 \\
\hline \multicolumn{6}{|c|}{ Independent variables } \\
\hline TeamRes & 464 & -3.39 & 2.15 & -0.001 & 0.98 \\
\hline IndRes & 464 & -3.29 & 2.31 & -0.001 & 0.97 \\
\hline \multicolumn{6}{|l|}{ Culture } \\
\hline PDI & 464 & 39 & 81 & 43.89 & 12.48 \\
\hline IDV & 464 & 30 & 91 & 81.88 & 18.08 \\
\hline MAS & 464 & 52 & 69 & 60.04 & 5.28 \\
\hline UAI & 464 & 46 & 82 & 50.18 & 10.73 \\
\hline LTO & 464 & 24 & 36 & 28.47 & 4.59 \\
\hline IVR & 464 & 68 & 97 & 70.94 & 8.76 \\
\hline \multicolumn{6}{|l|}{ Controls } \\
\hline Life cycle stage & 464 & 1 & 6 & 4.01 & 1.38 \\
\hline Turbulence & 464 & 1 & 5 & 2.70 & 0.69 \\
\hline Profitability & 464 & 1 & 5 & 3.65 & 0.96 \\
\hline \multicolumn{6}{|l|}{ Size } \\
\hline Small-Medium & 96 & 0 & 1 & 0.21 & 0.41 \\
\hline Large & 141 & 0 & 1 & 0.30 & 0.46 \\
\hline Very large & 227 & 0 & 1 & 0.49 & 0.50 \\
\hline \multicolumn{6}{|l|}{ Sector } \\
\hline Primary sector & 4 & 0 & 1 & 0.01 & 0.09 \\
\hline Secondary sector & 186 & 0 & 1 & 0.40 & 0.49 \\
\hline Tertiary sector & 192 & 0 & 1 & 0.41 & 0.49 \\
\hline Others & 82 & 0 & 1 & 0.18 & 0.38 \\
\hline
\end{tabular}

\section{Results}

The companies are all from the NAFTA region and include 47 Mexican (10.1\%), 124 Canadian (26.7\%), and 293 American (63.1\%) companies. Although the three countries are all from North America, studying cultural differences in the NAFTA region is valuable. Following Borycki et al. (1998), both the United States and Mexico, in terms of Hofstede's dimensions, are at virtual extremes. Moreover, Mac$\mathrm{Nab}$ et al. (2007) has also conducted an empirical study in the NAFTA region with a rather homogeneous cultural sample (Canada- $N=476$; the US- $N=463$; and Mexico- $N=248$ ), where they too found that some of Hofstede's cultural dimensions are significant; in their case in relation to ethics management tools. Namely, there is a significant negative relation between Power Distance (PDI) and internal reporting and a significant positive relation between Uncertainty Avoidance (UAI) and internal reporting, as well as whistle-blowing. Table 2 provides the descriptive statistics for all variables of our study.

The F-statistics (Table 3) indicate that the regression models are statistically significant for the direct effect of national culture on organizational resilience. 
Table 3 Regression results for national culture as independent variable

\begin{tabular}{|c|c|c|c|c|c|c|}
\hline & Model 1 & Model 2 & Model 3 & Model 4 & Model 5 & Model 6 \\
\hline \multicolumn{7}{|l|}{ Culture variable } \\
\hline Power Distance (H1) & $0.056^{*}$ & - & - & - & - & - \\
\hline Individualism (H2) & - & $-0.064^{* *}$ & - & - & - & - \\
\hline Masculinity (H3) & - & - & 0.006 & - & - & - \\
\hline $\begin{array}{l}\text { Uncertainty avoidance } \\
\text { (H4) }\end{array}$ & - & - & - & $0.060^{*}$ & - & - \\
\hline $\begin{array}{l}\text { Long-term orientation } \\
\text { (H5) }\end{array}$ & - & - & - & - & 0.012 & - \\
\hline Indulgence (H6) & - & - & - & - & - & $0.058^{*}$ \\
\hline \multicolumn{7}{|l|}{ Independent variables } \\
\hline Team resilience & $0.275^{* * *}$ & $0.274^{* * * *}$ & $0.278^{* * *}$ & $0.275^{* * *}$ & $0.279^{* * *}$ & $0.275^{* * * *}$ \\
\hline Individual resilience & $0.478^{* * * *}$ & $0.479^{* * *}$ & $0.479^{* * * *}$ & $0.478^{* * * *}$ & $0.480^{* * *}$ & $0.478^{* * * *}$ \\
\hline \multicolumn{7}{|l|}{ Control variables } \\
\hline Profitability & $0.085^{* *}$ & $0.087^{* * *}$ & $0.079^{* *}$ & $0.086^{* *}$ & $0.079^{* *}$ & $0.086^{* *}$ \\
\hline Turbulence & -0.036 & -0.036 & -0.040 & -0.036 & -0.040 & -0.036 \\
\hline Life cycle stage & 0.000 & 0.000 & -0.002 & 0.000 & -0.002 & 0.000 \\
\hline \multicolumn{7}{|l|}{ Dummy variables } \\
\hline \multicolumn{7}{|l|}{ Size } \\
\hline Small-Medium & 0.011 & 0.013 & 0.010 & 0.012 & 0.013 & 0.011 \\
\hline Large & 0.013 & 0.014 & 0.011 & 0.013 & 0.012 & 0.013 \\
\hline \multicolumn{7}{|l|}{ Economic sector } \\
\hline $\begin{array}{l}\text { Primary economic } \\
\text { sector }\end{array}$ & -0.003 & -0.005 & -0.003 & -0.004 & -0.005 & -0.003 \\
\hline $\begin{array}{l}\text { Secondary economic } \\
\text { sector }\end{array}$ & -0.034 & -0.032 & -0.032 & -0.033 & -0.030 & -0.034 \\
\hline $\begin{array}{l}\text { Tertiary economic } \\
\text { sector }\end{array}$ & -0.001 & -0.001 & 0.002 & -0.001 & 0.003 & -0.001 \\
\hline \multicolumn{7}{|l|}{ Other controls } \\
\hline Missing value & -0.024 & -0.025 & -0.024 & -0.024 & -0.025 & -0.024 \\
\hline Adjusted R2 & 0.550 & 0.551 & 0.547 & 0.551 & 0.547 & 0.551 \\
\hline $\mathbf{F}$ & $48.239^{* * *}$ & $48.418^{* * * *}$ & $47.645^{* * *}$ & $48.319^{* * * *}$ & $47.664^{* * *}$ & $48.265^{* * *}$ \\
\hline
\end{tabular}

$N=464$

Significance levels based on two-tailed tests

Standardized regression coefficients are reported

$* p<0.10$

$* * p<0.05$

$* * * p<0.01$

Results indicate that organizational resilience is significantly predicted by national culture with regard to the dimensions of individualism $(\beta=-0.064, p=0.043)$, uncertainty avoidance $(\beta=0.060, p=0.058)$, and indulgence $(\beta=0.058, p=0.069)$. Although the magnitude of the regression coefficients is small, it is statistically significant. The findings support hypotheses H2, H4, and H6. Hypothesis H3 is also supported by findings showing that there is no significant relationship between resilience and masculinity. The first hypothesis (H1) is rejected. A negative relationship was postulated, but findings indicate a significantly positive relationship 
between PDI and organizational resilience $(\beta=0.056, p=0.075)$. Hypothesis (H5), where a positive relationship between LTO and organizational resilience was predicted, was not significant, and thus, H5 is not supported. Organizational resilience is further highly positively correlated to team resilience, individual resilience, and profitability across all models $(p<0.001)$ (see Table 3 ).

Multicollinearity was not evident in any model. The variance inflation factor was below 1.5 for all variables included, and for all models except for the variable team resilience and individual resilience, which had a VIF of maximum 3.3 in all models.

Furthermore, three robustness checks have been conducted. First, Aycan (2000) and Lytle et al. (1995) suggest type II hypotheses of cultural research, that is, culture is treated as the moderator. This is especially interesting for the dimensions where no direct effect could be found, that is, masculinity and long-term orientation. Thus, models where each cultural dimension was added to the regression model as interaction terms at the team and individual level were tested. Results showed that including these interaction terms in the basic model did not enhance model statistics, due to the adjusted $\mathrm{R}$, and the significance of national culture as an independent variable remaining the same. Moreover, the multicollinearity in the models with moderating interaction terms exceeds the threshold $(\mathrm{VIF}<10)$.

Second, as we already pointed out in our methodology section, there are no biases such as a pattern of missing values. Thus, we performed a Bootstrapping analysis ( $N=20,000$ samples with replacement) to test for the accuracy of our model in regard to our sample that includes many firms of the same cultural cluster. All significant associations for an effect of Hofstede's cultural dimensions, as well as team and individual resilience on organizational resilience remained qualitatively unchanged within a 95\% confidence interval. Only profitability showed slightly changing significance levels in model 1 (from $<0.05$ to $p<0.01$ ), model 2 (from $<0.01$ to $p<0.05$ ), model 4 (from $<0.05$ to $p<0.01$ ), and model 6 (from $<0.05$ to $p<0.01$ ). Thus, our model is robust and delivers an indication for an effect of national culture on organizational resilience.

Third, we tested models where we included the cultural dimension score from the GLOBE project instead of Hofstede's dimensions in order to validate our findings with Hofstede. Results here showed that culture has a direct effect; the results for models where culture is treated as a main effect are comparable to the findings of the models applied with Hofstede dimensions. Moreover, the results for the models where culture moderated the relationship to organizational resilience remained stable. The same was found for the Hofstede dimensions.

In sum, there is a strong indication of a cultural effect on organizational resilience, as the cultural dimensions of both the Hofstede and Globe frameworks are significant.

\section{Discussion}

Results indicate that organizational resilience is significantly predicted by the cultural dimensions of power distance, individualism, uncertainty avoidance, and indulgence. 
For hypothesis H1, we predicted a negative relationship between PDI and organizational resilience, however, our findings showed that PDI appears to relate positively to organizational resilience. One explanation for this finding could be that in times of turbulence-including crises or unexpected events-a collective acceptance of power could result in a positive outcome, as employees will carry out strategies developed by their superiors without the need for lengthy prior discussions. PDI determines resource accessibility, as cultures with high PDI are less democratic in terms of resource distribution (Chakrabarty 2009). Responsibilities that are needed for fast reactions are clear, allow for the speedy distribution of necessary resources. This might enable the organization and its teams to respond quickly and effectively. In this way, power distance can be construed as beneficial to an extent, although the finding is surprising, as an alternative explanation is also a possibility-namely, that cultures with a low PDI score might favor a more decentralized power allocation. A decentralized power allocation allows for faster local responses in crisis situations, so local knowledge can be applied more effectively. Therefore, future research should validate these relationships in a different and more heterogeneous sample. Managerial implications based on our findings show that clear chains of responsibility should be created - especially for times of crises - to support the distribution of tasks and responsibilities to foster organizational resilience. Management tools such as guidelines, manuals, workshops, employee training, a code of conduct and a clear definition and communication of corporate values and goals can be supportive in this vein.

As postulated in hypothesis H2, individualism (IDV) is negatively related to organizational resilience. High scores on individualism lead to a lower organizational resilience, which is supported by the results of this study. Collectivistic cultures are strongly oriented towards sharing the same values and putting the interests of their group first (Hofstede 2001; Newman and Nollen 1996). They are closely connected to their network, and have strong ties with other members of their group (Hofstede 2001; Luczak et al. 2010; Rinne et al. 2012), which are both essential values for organizational resilience. Moreover, collectivism strengthens transformational leadership (Walumbwa and Lawler 2003), which supports the build-up and establishment of organizational resilience. Consequently, managerial implications show that a shared purpose and identity can foster organizational resilience (Ishak and Williams 2018), which can be achieved with a transformational corporate leadership through applying management tools, such as setting a business vision and mission that creates a common corporate identity and a sense of togetherness. This both appeals emotionally and increases awareness and understanding of mutually desired corporate goals (Walumbwa and Lawler 2003), and can be supported by teambuilding events and encouraging corporate relationship management and networking among employees. These managerial implications are supported by the analysis of Bhagat et al. (2010) that emotion-focused coping is beneficial in collectivistic cultural contexts.

As expected, masculinity (MAS) does not significantly predict organizational resilience. Although feminine cultures are described as being more socially-oriented and encouraging of shared values (Chiaburu et al. 2015), masculine cultures are more performance-oriented (Luczak et al. 2014). This cultural dimension is measured 
through two opposite ends (masuclinity vs. feminity), therefore both effects neutralize each other. However, both aspects are important for organizational resilience. The other cultural dimensions are more relevant to organizational resilience and, following Hofstede's (2006) description of this dimension, MAS divides countries in a totally different manner than that of individualism vs. collectivism. A country can be collectivistic but feminine (e.g., Thailand), and collectivistic and masculine (e.g., Japan) and thus, no distinct managerial implications can be drawn from the relationship of this cultural dimension with organizational resilience.

We expected uncertainty avoidance to be positively associated with organizational resilience (H4), which is supported by our findings. This means that with a higher score of uncertainty avoidance, organizational resilience increases. Thus, organizations in those countries put more emphasis on developing an awareness capability (McCann and Selsky 2012) which includes anticipation of events and continuously monitoring and scanning the environment to reduce risks and avoid as many shocks or unexpected events as possible. This might result in developing enterprise-wide risk management systems (Starr et al. 2003), complexity absorbing routines (Lengnick-Hall and Beck 2005) such as scenario planning, and capabilities such as organizational ambidexterity (McCann and Selsky 2012). As a managerial implication, organizations should act proactively and thus, attempt to actively shape the corporate environment to create better business conditions that also help to foster organizational resilience. These findings are supported by the empirical study of Borekci et al. (2014). Suitable management tools can be a long-term stakeholder management, scenario planning combined with employee training on crises responses, and a long-term business vision which provides orientation and guidance. Moreover, a broader business focus that covers product segments or product lines and accompanying services — rather than merely centering on a single product—can be beneficial.

Long-term orientation has no effect on organizational resilience; hypothesis 5 is not supported. This cultural dimension explains how people deal with business relations, and the results of this study indicate that both the long-term approach of having long-term personal relationships with business partners based on trust, as well as short-term transaction, competition, and result oriented relationships, may be beneficial. The type of relationship that must be established depends on the business environment. Thus, the dimension of long-term orientation versus short-term orientation is not related to organizational resilience. In this case, the finding might occur due to the sample. In terms of long-term orientation, all countries have a relatively similar score and are significantly short-term oriented; it must also be highlighted that no variance was found in terms of these dimensions. Therefore, a sample with a higher variance might provide different findings. Another explanation can be seen in the dimension itself, in that both orientations might facilitate resilience in different ways. On the one hand, long-term orientation is related to network orientation (McCann and Selsky 2012) such as efforts in building healthy and beneficial networks and alliances, with a future-oriented focus (Borekci et al. 2014). Moreover, an empirical study from Sulphey (2020) concludes that a long-term orientation manifested in corporate long-term planning strengthens organizational resilience. On the other hand, short-term orientation is also related to action-orientation (McCann and 
Selsky 2012), which means that a pragmatic and quick response is beneficial to organizational resilience. Competition orientation is also relevant; thus, companies may react to changing market conditions faster. This assumption that traits of both longterm and short-term orientation can increase organizational resilience is supported by the findings of Andersson et al. (2019), which suggest that a combination of both long-term and short-term traits might be beneficial. However, further research must be done in this field as Andersson et al. (2019) also emphasize. Consequently, based on the empirical findings of our study, no distinct managerial implications can be drawn from the relationship of this cultural dimension to organizational resilience.

Indulgence (versus restraint) is positively correlated with organizational resilience because members of indulgent cultures actively respond to, and manage vulnerabilities, threats, and weaknesses and also look for external help and advice. They tend to be optimistic and are more likely to be intrinsically motivated in their zest for life. Contrastingly, restraint cultures tend to accept vulnerabilities, or are reluctant to express them to outsiders, or seek out help or advice due to strict social norms. Their pessimistic tendencies, combined with such tight rules and regulations may diminish the scope for interpretation and thus, curb creative thinking. Consequently, this might lead to fewer alternative solutions and less flexibility that might be needed in times of crises. All these factors have a negative impact on organizational resilience, however, literature on the cultural dimension of indulgence versus restraint, and its relationship to organizational resilience is very sparse and thus, further research is necessary. As a managerial implication, creative thinking should be encouraged to facilitate organizational resilience-through management tools such as workshops and feedback loops to encourage proactive creative thinking. Moreover, corporate rules and regulations must be revised to better find a balance between the necessary distribution of tasks and responsibilities, and ensuring sufficient space for creative thinking.

\section{Limitations and Future Research}

This paper also faced some limitations with regard to the sample-conducted in the NAFTA region. First, companies from Mexico are underrepresented in the sample. Second, Canada and the United States are considered to belong to the same cultural cluster-the Anglo-American cluster (Ronen and Shenkar 2013). A more internationally-diverse sample of countries, including European, African and Asian countries, may reveal an even stronger direct effect of national culture on organizational resilience. The small number of countries (not more than three different countries) for comparison also limited scope; however, the majority of studies in cross-cultural research face this limitation (Tsui et al. 2007). Moreover, as Tsui et al. (2007) emphasize, cross-national research faces problems with "unmatching samples", although, above all, it is crucial that each sample properly represents the particular country surveyed (Hofstede 2001; Tsui et al. 2007). Robustness checks as the Bootstrapping analysis support our findings, which show that national culture directly effects organizational resilience even in a rather homogeneous cultural cluster. Furthermore, MacNab et al. (2007) also conducted an empirical study in 
the NAFTA region with a rather homogeneous cultural sample (Canada- $N=476$; the US- $N=463$; and Mexico- $N=248$ ), and found that some of Hofstede's cultural dimensions are significant; in their case, in relation to ethics management tools. They found a significantly negative relationship between PDI and internal reporting, and a significantly positive relationship between UAI and internal reporting, as well as whistle-blowing. We assumed that in a more equally-distributed sample and a more heterogeneous cultural cluster, the magnitude of the cultural effect would be stronger-representing a promising avenue for future research.

Additionally, the data did not allow for a differentiation between Anglo-Canadian and French-Canadian backgrounds in the sample, so Canadians have been classified as one cultural group, as with Hofstede's cultural framework (Hofstede 2001). Still, this classification was legitimate within this study, as the focus was on the NAFTA region, and the Anglo-Canadian population accounts for roughly $80 \%$ of the overall Canadian population (Statistics Canada 2012). Future studies, however, could investigate intra-Canadian differences for the Anglo- and French-Canadian regions.

In general, there is a discussion in the current research literature as to whether or not the six cultural dimensions of Hofstede's model are enough to display a complex term such as culture (Baskerville 2003; McSweeney 2002). Based on our analysis, it was sufficient; applying Hofstede's framework ensured a better development of our hypotheses and better comparison to other research in this field. Moreover, the robustness checks (bootstrapping and the application of the Globe framework) confirmed the results of our analysis - that there are cultural effects on organizational resilience. Furthermore, the resilience dataset applied in our analysis does not require a national culture framework that further distinguishes multiethnic countries like India, Arab, or African countries, which was a major point of criticism about Hofstede's framework. Besides, a new comprehensive cultural framework comparable to Hofstede with newly collected data has not been published in recent years (Ronen and Shenkar 2013).

Although the age of our dataset may be perceived as old, we followed the advice of Zimmerman (2008) and Stolowy (2017) who posit that in our case, with a new research field and unavailable new data, it is feasible to draw new knowledge from old data to open a new avenue for further research. However, as we pointed out in our study, future research and more sophisticated studies on the relationship between resilience and culture, e.g. with more detailed cultural models, should to be pursued.

Another limitation relates to the available data. Since our data includes three different levels, namely, organizational, group (team), and individual level, our study can also be considered a multilevel study. The original data collection and constructs were not conceptualized as a multilevel study. Nonetheless, we investigated the relationship of the individual (micro) and team level (meso) to organizational level (macro). We found that individual as well as team resilience strongly influences organizational resilience. However, since our data only includes single-level responses about the meso and micro level, our findings are limited with regard to that issue. Even so, studying the topic of this paper from a multilevel perspective that includes multi-level responses is a promising future research avenue. 


\section{Conclusion}

The findings of this study show that national culture affects an organization's resilience. These findings were already significant for the NAFTA region, in which USA and Canada belong to the same cultural cluster. This study shows that organizational resilience is context-specific; it is influenced by external factors and is not only path-dependent and intra-organizational or idiosyncratic to the organization. This has several practical implications. In order to build or strengthen capabilities, processes, and resources that lead to organizational resilience, companies that operate beyond national borders should be aware of the cultural aspects that influence mechanisms of organizations resilience. The relationship between headquarters and subsidiaries in multinational companies must also be taken into account, since different national cultures and possible organizational subcultures might interfere with the process of building and maintaining organizational resilience. There are also particular implications for human resources in so far as, depending on the cultural background, different HR practices, strategies, or trainings have to be applied for organizational resilience. The globalization of labor has led to cross-cultural workforce and teams, and this has to be taken into account in managerial decisions to facilitate resilience. Cultural differences must be considered in terms of relationship and network building, which are essential for mitigating and buffering sudden shocks or unexpected events. 


\section{Appendix}

Table 4 Survey items

\begin{tabular}{|c|c|c|c|}
\hline \multirow{2}{*}{$\begin{array}{l}\text { Variable } \\
\text { Organizational } \\
\text { resilience }\end{array}$} & \multicolumn{2}{|c|}{ Short description } & \multirow{2}{*}{$\begin{array}{l}\text { Item } \\
\text { Our Organization is open to change }\end{array}$} \\
\hline & OR1 & $\begin{array}{l}\text { Openness towards } \\
\text { change }\end{array}$ & \\
\hline & OR2 & Sensemaking & $\begin{array}{l}\text { Our Organization is good at making sense of ambigu- } \\
\text { ous, uncertain situations }\end{array}$ \\
\hline & OR3 & $\begin{array}{l}\text { Knowledge col- } \\
\text { lection }\end{array}$ & $\begin{array}{l}\text { Our Organization actively and widely scans for new } \\
\text { information about what's going on }\end{array}$ \\
\hline & OR4 & $\begin{array}{l}\text { Investing in net- } \\
\text { works }\end{array}$ & $\begin{array}{l}\text { Our Organization invests sufficient attention and re- } \\
\text { sources to manage key external relationships (vendors, } \\
\text { customers, etc.) }\end{array}$ \\
\hline & OR5 & $\begin{array}{l}\text { Ability to take } \\
\text { opportunities }\end{array}$ & $\begin{array}{l}\text { Our Organization takes advantage of opportunities } \\
\text { quickly }\end{array}$ \\
\hline & OR6 & Resource usage & $\begin{array}{l}\text { Our Organization is good at quickly deploying and } \\
\text { redeploying resources to support execution }\end{array}$ \\
\hline & OR7 & Deep talent pool & Our Organization has a deep talent pool \\
\hline & OR8 & Ability to absorb & $\begin{array}{l}\text { Our Organization can absorb a severe surprise or shock } \\
\text { without failing —not 'fragile' }\end{array}$ \\
\hline & OR9 & $\begin{array}{l}\text { Ability to recover } \\
\text { fast }\end{array}$ & $\begin{array}{l}\text { Our Organization reacts quickly and effectively after } \\
\text { taking a big hit }\end{array}$ \\
\hline & OR10 & Shared purpose & $\begin{array}{l}\text { Our Organization has a strong sense of identity and } \\
\text { purpose that can survive anything }\end{array}$ \\
\hline & OR11 & $\begin{array}{l}\text { External support } \\
\text { network }\end{array}$ & $\begin{array}{l}\text { Our Organization has a strong support network of } \\
\text { external alliances and partnerships }\end{array}$ \\
\hline & OR12 & $\begin{array}{l}\text { Ability to exploit } \\
\text { resources }\end{array}$ & $\begin{array}{l}\text { Our Organization is good at enterprise-wide risk as- } \\
\text { sessment and management }\end{array}$ \\
\hline & OR13 & $\begin{array}{l}\text { Expanding net- } \\
\text { work }\end{array}$ & $\begin{array}{l}\text { Our Organization is expanding its external alliances } \\
\text { and partnerships }\end{array}$ \\
\hline & OR14 & $\begin{array}{l}\text { Ability to break } \\
\text { down barriers }\end{array}$ & $\begin{array}{l}\text { Our Organization continuously breaks down bound- } \\
\text { aries and barriers }\end{array}$ \\
\hline & OR15 & Resource access & $\begin{array}{l}\text { Our Organization has "deep pockets"-access to capi- } \\
\text { tal and resources to weather anything }\end{array}$ \\
\hline & OR16 & $\begin{array}{l}\text { Evaluation of } \\
\text { external alliance }\end{array}$ & $\begin{array}{l}\text { Our Organization is actively reevaluating risky external } \\
\text { alliances and partnerships }\end{array}$ \\
\hline & OR17 & Shared values & $\begin{array}{l}\text { Our Organization has clearly defined and widely held } \\
\text { values and beliefs }\end{array}$ \\
\hline
\end{tabular}


Table 4 (Continued)

\begin{tabular}{|c|c|c|c|}
\hline \multirow{2}{*}{$\begin{array}{l}\text { Variable } \\
\text { Team } \\
\text { resilience }\end{array}$} & \multicolumn{2}{|c|}{ Short description } & \multirow{2}{*}{$\frac{\text { Item }}{\text { Our Teams are open to change }}$} \\
\hline & TR1 & $\begin{array}{l}\text { Openness towards } \\
\text { change }\end{array}$ & \\
\hline & TR2 & Sensemaking & $\begin{array}{l}\text { Our Teams are good at making sense out of ambigu- } \\
\text { ous, uncertain situations }\end{array}$ \\
\hline & TR3 & $\begin{array}{l}\text { Tolerance for } \\
\text { ambiguity }\end{array}$ & $\begin{array}{l}\text { Our Teams have a high tolerance for ambiguity and } \\
\text { uncertainty }\end{array}$ \\
\hline & TR4 & $\begin{array}{l}\text { Ability to quickly } \\
\text { adapt }\end{array}$ & $\begin{array}{l}\text { Our Teams can quickly change roles and responsibili- } \\
\text { ties }\end{array}$ \\
\hline & TR5 & $\begin{array}{l}\text { Ability to deal } \\
\text { with stress }\end{array}$ & Our Teams function well during pressure and stress \\
\hline & TR6 & Big picture & $\begin{array}{l}\text { Our Teams see the big picture—can take a systems } \\
\text { view }\end{array}$ \\
\hline & TR7 & $\begin{array}{l}\text { Ability to multi- } \\
\text { task }\end{array}$ & $\begin{array}{l}\text { Our Teams are good multi-taskers—can do many } \\
\text { things at once }\end{array}$ \\
\hline & TR8 & Decision-making & $\begin{array}{l}\text { Our Teams are well-integrated into key decision-mak- } \\
\text { ing processes }\end{array}$ \\
\hline & TR9 & Persistence & $\begin{array}{l}\text { Our Teams have great persistence-can demonstrate } \\
\text { moral and physical courage }\end{array}$ \\
\hline & TR10 & Action-oriented & $\begin{array}{l}\text { Our Teams are action-oriented—quickly take advan- } \\
\text { tage of situations }\end{array}$ \\
\hline & TR11 & Shared values & $\begin{array}{l}\text { Our Teams have adopted the organization's values and } \\
\text { beliefs }\end{array}$ \\
\hline & TR12 & Learning & $\begin{array}{l}\text { Our Teams are active learners-quickly acquire and } \\
\text { apply new skills and knowledge }\end{array}$ \\
\hline & TR13 & Resource access & Our Teams have access to the resources to act \\
\hline & TR14 & Deep experience & $\begin{array}{l}\text { Our Teams have deep experience-they've 'seen and } \\
\text { done' it all }\end{array}$ \\
\hline & TR15 & Problem-solvers & $\begin{array}{l}\text { Our Teams have well-developed group skills (e.g., } \\
\text { problem-solving) }\end{array}$ \\
\hline & TR16 & Mentors & $\begin{array}{l}\text { Our Teams have members who mentor, coach, and } \\
\text { support each other }\end{array}$ \\
\hline & TR17 & Creativity & $\begin{array}{l}\text { Our Teams can think outside the box-are inventive } \\
\text { and creative }\end{array}$ \\
\hline
\end{tabular}


Table 4 (Continued)

\begin{tabular}{|c|c|c|c|}
\hline \multirow{2}{*}{ 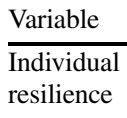 } & \multicolumn{2}{|c|}{ Short description } & \multirow{2}{*}{$\frac{\text { Item }}{\text { Our People are open to change }}$} \\
\hline & IR1 & $\begin{array}{l}\text { Openness towards } \\
\text { change }\end{array}$ & \\
\hline & IR2 & Sensemaking & $\begin{array}{l}\text { Our People are good at making sense of ambiguous, } \\
\text { uncertain situations }\end{array}$ \\
\hline & IR3 & $\begin{array}{l}\text { Tolerance for } \\
\text { ambiguity }\end{array}$ & $\begin{array}{l}\text { Our People have a high tolerance for ambiguity and } \\
\text { uncertainty }\end{array}$ \\
\hline & IR4 & $\begin{array}{l}\text { Ability to quickly } \\
\text { adapt }\end{array}$ & $\begin{array}{l}\text { Our People can quickly change roles and responsibili- } \\
\text { ties }\end{array}$ \\
\hline & IR5 & $\begin{array}{l}\text { Ability to deal } \\
\text { with stress }\end{array}$ & Our People function well during pressure and stress \\
\hline & IR6 & Big picture & $\begin{array}{l}\text { Our People see the big picture-can take a systems } \\
\text { view }\end{array}$ \\
\hline & IR7 & $\begin{array}{l}\text { Ability to multi- } \\
\text { task }\end{array}$ & $\begin{array}{l}\text { Our People are good multi-taskers-able to do many } \\
\text { things at once }\end{array}$ \\
\hline & IR8 & Persistence & $\begin{array}{l}\text { Our People have great persistence-can demonstrate } \\
\text { moral and physical courage }\end{array}$ \\
\hline & IR9 & Action-oriented & $\begin{array}{l}\text { Our People are action-oriented-quickly take advan- } \\
\text { tage of situations }\end{array}$ \\
\hline & IR10 & Shared values & $\begin{array}{l}\text { Our People have adopted the organization's values and } \\
\text { beliefs }\end{array}$ \\
\hline & IR11 & Learning & $\begin{array}{l}\text { Our People are active learners_-quickly acquire and } \\
\text { apply new skills and knowledge }\end{array}$ \\
\hline & IR12 & Resource access & Our People have access to the resources to act \\
\hline & IR13 & Deep experience & $\begin{array}{l}\text { Our People have deep experience-they've seen and } \\
\text { done it all }\end{array}$ \\
\hline & IR14 & Optimistic & $\begin{array}{l}\text { Our People are optimistic_-have strong, positive self- } \\
\text { concepts }\end{array}$ \\
\hline & IR15 & Creativity & $\begin{array}{l}\text { Our People think outside the box-are inventive and } \\
\text { creative }\end{array}$ \\
\hline & IR16 & Mentors & Our People are good mentors and coaches \\
\hline & IR17 & Technology usage & Our People know and use technology effectively \\
\hline
\end{tabular}

Acknowledgements The authors give special thanks to John Selsky, Joseph McCann, and James Lee for providing us with this great data set for further analysis. We especially thank Thomas Guenther and John Selsky for comments and feedback on earlier versions of this paper. Julia Hillmann thanks the Dresden Leibniz Graduate School (Leibniz Institute of Ecological Urban and Regional Development, Dresden, Germany) for receiving a PhD scholarship to do this research.

Author Contribution Conceptualization-Bernhard Fietz, Julia Hillmann, Edeltraud Guenther;

Data preparation-Bernhard Fietz, Julia Hillmann;

Data evaluation-Bernhard Fietz, Julia Hillmann;

Interpretation of raw data-Bernhard Fietz, Julia Hillmann;

Interpretation of results_-Bernhard Fietz, Julia Hillmann;

Writing-Bernhard Fietz, Julia Hillmann, Edeltraud Guenther 
Open Access This article is licensed under a Creative Commons Attribution 4.0 International License, which permits use, sharing, adaptation, distribution and reproduction in any medium or format, as long as you give appropriate credit to the original author(s) and the source, provide a link to the Creative Commons licence, and indicate if changes were made. The images or other third party material in this article are included in the article's Creative Commons licence, unless indicated otherwise in a credit line to the material. If material is not included in the article's Creative Commons licence and your intended use is not permitted by statutory regulation or exceeds the permitted use, you will need to obtain permission directly from the copyright holder. To view a copy of this licence, visit http://creativecommons.org/licenses/by/4. $0 /$.

Conflict of interest B. Fietz, J. Hillmann and E. Guenther declare that they have no competing interests.

\section{References}

Acar, William, and Frank L. Winfrey. 1994. The resilient organization: sustaining organizational renewal and performance. Journal of Strategic Change 3:165-173.

Alas, Ruth, Nancy Papalexandris, Eleanna Galanaki, and Katrin Niglas. 2011. Managerial values and employee commitment in a cultural context. Transformations in Business \& Economics 10:42-59.

Alesina, Alberto, Arnaud Devleeschauwer, William Easterly, Sergio Kurlat, and Romain Wacziarg. 2003. Fractionalization. Journal of Economic Growth 8(2):155-194.

Alesina, Alberto, Stelios Michalopoulos, and Elias Papaioannou. 2016. Ethnic Inequality. Journal of Political Economy 124(2):428-488.

Allison, Paul D. 2001. Missing data-quantitative applications in the social sciences. Thousand Oaks: SAGE.

American Management Association. 2006. Agility and resilience in the face of continuous change: a global study of current trends and future possibilities. http://www.amanet.org/images/hri-agility06.pdf. Accessed 27 Oct 2016.

Andersson, Thomas, Mikeal Cäker, Stefan Tengblad, and Mikael Wickelgren. 2019. Building traits for organizational resilience through balancing organizational structures. Scandinavian Journal of Management 35(1):36-45.

Ang, Siah Hwee. 2014. Research design for business \& management. London: SAGE.

Aycan, Zeynep. 2000. Cross-cultural industrial and organizational psychology: contributions, past developments, and future directions. Journal of Cross-Cultural Psychology 31(1):110-128.

Bartlett, Christopher A., and Sumantra Ghoshal. 2003. Managing across borders: the transnational solution, 2nd edn., Boston: Harvard Business School Press.

Baskerville, Rachel F. 2003. Hofstede never studied culture. Accounting, Organizations and Society 28(1):1-14.

Baum, James A., and Timothy J. Rowley. 2005. Companion to organizations: an introduction. In The Blackwell companion to organizations, ed. J.A. Baum, 1-34. Oxford: Blackwell Business.

Beugelsdijk, Sjoerd, Robbert Maseland, and André van Hoorn. 2015. Are Scores on Hofstede's Dimensions of National Culture Stable over Time? A Cohort Analysis. Global Strategy Journal 5(3):223-240.

Bhagat, Rabi S., Balaji Krishnan, Terry A. Nelson, Karen Moustafa Leonard, David L. Ford Jr, and Tejinder K. Billing. 2010. Organizational stress, psychological strain, and work outcomes in six national contexts: a closer look at the moderating influences of coping styles and decision latitude. Cross Cultural Management: An International Journal 17(1):10-29.

Boin, Arjen, and Michel J.G. van Eeten. 2013. The resilient organization a critical appraisal. Public Management Review 15(3):429-445.

Bonanno, George A. 2004. Loss, trauma, and human resilience: Have we underestimated the human capacity to thrive after extremely aversive events? American Psychologist 59(1):20-28.

Bono, Joyce E., and Gerry McNamara. 2011. Publishing in AMJ-part 2: research design. Academy of Management Journal 54 (4): 657-660. https://doi.org/10.5465/amj.2011.64869103.

Borekci, Dilek, Yasin Rofcanin, and Meral Sahin. 2014. Effects of organizational culture and organizational resilience over subcontractor riskiness. European business review 26(1):1-22.

Borycki, Christine, Ron G. Thorn, and Jane LeMaster. 1998. Job satisfaction and organization commitment: a comparison of United States and Mexico employees. International Journal of Commerce and Management 8(3/4):7-25.

Bradfield, Ron, George Wright, George Burt, George Cairns, and Kees van der Heijden. 2005. The origins and evolution of scenario techniques in long range business planning. Futures 37(8):795-812. 
Brewer, Paul, and Sunil Venaik. 2014. The ecological fallacy in national culture research. Organization Studies 35(7):1063-1086.

Carmeli, Abraham, and Gideon D. Markman. 2011. Capture, governance, and resilience: strategy implications from the history of Rome. Strategic Management Journal 32(3):322-341.

Carmeli, Abraham, Yair Friedman and Asher Tishler. 2013. Cultivating a resilient top management team: The importance of relational connections and strategic decision comprehensiveness. Safety Science 51(1):148-159.

Celani, Anthony, and Kevin Tasa. 2010. We're all in this together: examining associations between collectivistic group norms, collective efficacy and team performance. Academy of Management Proceedings 2010(1):1-6. https://doi.org/10.5465/ambpp.2010.54497579.

Chakrabarty, Subrata. 2009. The influence of national culture and institutional voids on family ownership of large firms: a country level empirical study. Journal of International Management 15(1):32-45.

Chan, Joseph W.K. 2011. Enhancing organisational resilience: application of viable system model and MCDA in a small Hong Kong company. International Journal of Production Research 49(18):5545-5563.

Chapman, Michael T., Robin Lines, Monique Crane, Kagan J. Ducker, Nikos Ntoumanis, Peter Peeling, Sharon K. Parker, et al, 2020. Team resilience: a scoping review of conceptual and empirical work. Work \& Stress 34(1):57-81.

Chermack, Thomas J., Wendy Bodwell, and Maggie Glick. 2010. Two strategies for leveraging teams toward organizational effectiveness: scenario planning and organizational ambidexterity. Advances in Developing Human Resources 12(1):137-156.

Chewning, Lisa V., Lai Chih-Hui, and Marya L. Doerfel. 2013. Organizational resilience and using information and communication technologies to rebuild communication structures. Management Communication Quarterly 27(2):237-263.

Chiaburu, Dan S., Subrata Chakrabarty, Jiexin Wang, and Ning Li. 2015. Organizational support and citizenship behaviors: A comparative cross-cultural meta-analysis. Management International Review 55(5):707-736.

Child, Dennis. 2006. Essentials of factor analysis, 3rd edn., New York: Continuum.

Cho, Sunyoung, Lars Mathiassen, and Daniel Robey. 2006. Dialectics of resilience: a multi-level analysis of a telehealth innovation. Journal of Information Technology 22(1):24-35.

Chung, Jae-Eun, Brenda Sternquist, and Zhengyi Chen. 2006. Retailer-buyer supplier relationships: the Japanese difference. Journal of Retailing 82(4):349-355.

Clement, Viviane, and Jorge Rivera. 2017. From adaptation to transformation: An extended research agenda for organizational resilience to adversity in the natural environment. Organization \& Environment 30(4):346-365.

Cohen, Aaron. 2007. One nation, many cultures: a cross-cultural study of the relationship between personal cultural values and commitment in the workplace to in-role performance and organizational citizenship behavior. Cross-Cultural Research 41(3):273-300.

Cole, Jason C. 2008. How to deal with missing data. In Best Practices in Quantitative Methods, ed. J.W. Osborne, 214-238. Thousand Oaks: SAGE.

Collis, David J. 1991. A resource-based analysis of global competition: the case of the bearings industry. Strategic Management Journal 12(S1):49-68.

Congden, Steven W., Alexei V. Matveev, and David E. Desplaces. 2009. Cross-cultural communication and multicultural team performance: a German and American comparison. Journal of Comparative International Management 12(2):73-89.

Cooper, Robertson. 2013. The bank on your people: the state of well being and high performance culture in the financial sector. http://www.bwcharity. org.uk/sites/default/files/BWC_Research_Report.PDF. Accessed 15 July 2014.

Costello, Anna B., and Jason Osborne. 2005. Best practices in exploratory factor analysis: four recommendations for getting the most from your analysis.-Practical Assessment, Research \& Evaluation. Practical Assessment Research \& Evaluation 10(7):1-9.

Coutu, Diane L. 2002. How resilience works. Harvard Business Review 80(5):46-51.

Cox, Pamela L., Barry A. Friedman, and Thomas Tribunella. 2011. Relationships among cultural dimensions, national gross domestic product, and environmental sustainability. The Journal of Applied Business and Economics 12(6):46-56.

Crane, Diana. 1969. Social structure in a group of scientists: A test of the "Invisible College" hypothesis. American Sociological Review 34(3): 335-352. 
Danes, Sharon M., Lee Jinhee, Sayali Amarapurkar, Kathryn Stafford, George Haynes, and Katherine E. Brewton. 2009. Determinants of family business resilience after a natural disaster by gender of business owner. Journal of Developmental Entrepreneurship 14(4):333-354.

Daniels, Michael A., and Gary J. Greguras. 2014. exploring the nature of power distance: implications for micro- and macro-level theories, processes, and outcomes. Journal of Management 40(5):1202-1229.

DiLalla, David L., and Stephen J. Dollinger. 2006. Cleaning up data and running preliminary analyses. In The psychology research handbook: a guide for graduate students and research assistants, ed. Frederick T.L. Leong, James T. Austin, 241-253. Thousand Oaks: SAGE.

Doney, Patricia M., Joseph P. Cannon, and Michael R. Mullen. 1998. Understanding the influence of national culture on the development of trust. Academy of Management Review 23(3):601-620.

Duchek, Stephanie. 2020. Organizational resilience: a capability-based conceptualization. Business Research 13:215-246.

Dückers, Michel, Georg Frerks, and Jörn Birkmann. 2015. Exploring the plexus of context and consequences: an empirical test of a theory of disaster vulnerability. International Journal of Disaster Risk Reduction 13:85-95.

Dumitraşcu, Iulia, and Dănuţ D. Dumitraşcu. 2016. How culture and motivation interact in an international virtual project team. International Conference Knowledge-Based Organization 22(2):15.

Dyer, Jeffrey H., and Harbir Singh. 1998. The relational view: cooperative strategy and sources of interorganizational competitive advantage. Academy of Management Review 23(4):660-679.

Erez, Miriam, and P. Christopher Earley. 1993. Culture, self-identity, and work. New York: Oxford University Press.

Erez, Miriam, and Efrat Gati. 2004. A dynamic, multi-level model of culture: from the micro level of the individual to the macro level of a global culture. Applied Psychology 53(4):583-598.

Euwema, Martin C., Hein Wendt, and Hetty van Emmerik. 2007. Leadership styles and group organizational citizenship behavior across cultures. Journal of Organizational Behavior 28(8):1035-1057.

Farh, Jiing-Lih, Rick D. Hackett, and Jian Liang. 2007. Individual-level cultural values as moderators of perceived organizational support-employee outcome relationships in china: Comparing the effects of power distance and traditionality. Academy of Management Journal 50(3):715-729.

Freeman, Steven F., Larry Hirschhorn, and Marc Maltz. 2004. The power of moral purpose: Sandler O'Neill \& partners in the aftermath of September 11th, 2001. Organizational Development Journal 22(4):69-81.

French, Sandra L., and Tracey Q. Holden. 2012. Positive organizational behavior: a buffer for bad news. Business Communication Quarterly 7(5):208-220.

Gallego-Álvarez, Isabel, and Eduardo Ortas. 2017. Corporate environmental sustainability reporting in the context of national cultures: A quantile regression approach. International Business Review 26(2):337-353.

Gelfand, Michele J., Miriam Erez, and Zeynep Aycan. 2007. Cross-cultural organizational behavior. Annual Review of Psychology 58(1):479-514.

Gilbert, Clark G. 2005. Unbundling the structure of inertia: resource versus routine rigidity. Academy of Management Journal 48(5):741-763.

Gittell, Jody H., Kim Cameron, Sandy Lim, and Victor Rivas. 2006. Relationships, layoffs, and organizational resilience: airline industry responses to September 11. The Journal of Applied Behavioral Science 42(3):300-329.

Gladwell, Malcolm. 2011. Outliers: the story of success, 2nd edn., New York: Back Bay Books.

Goldman, Stephen L., Roger N. Nagel, and Kenneth Preiss. 1994. Agile competitors and virtual organizations: strategies for enriching the customer. New York: Van Nostrand Reinhold.

Grimmer, Martin, and Matthew Oddy. 2007. Violation of the psychological contract: the mediating effect of relational versus transactional beliefs. Australian Journal of Management 32(1):153-174.

Gunnestad, Arve. 2006. Resilience in a Cross-Cultural Perspective: How resilience is generated in different cultures. Journal of Intercultural Communication 11(1): w/o page. http://hdl.handle.net/11250/ 2564077

Gupta, Vipin, Nancy Levenburg, Lynda Moore, Jaideep Motwani, and Thomas V. Schwarz. 2010. Family business in sub-saharan Africa versus the middle east. Journal of African Business 11(2):146-162.

Hamel, Gary, and Liisa Välikangas. 2003. The quest for resilience. Harvard Business Review 81(9):52-63.

Heifetz, Ronald, Alexander Grashow, and Marty Linsky. 2009. Leadership in a (permanent) crisis. Harvard Business Review 87(7/8):62-69.

Helmreich, Robert L., and H. Clayton Foushee. 1993. Why crew resource management? Empirical and theoretical bases of human factors training in aviation. : Academic Press. 
Helmreich, Robert L., A. Wilhelm John, James R. Klinect, and Ashleigh C. Merritt. 2001. Culture, error and crew resource management. In Improving teamwork in organizations: applications of resource management training, ed. Eduardo Salas, Clint A. Bowers, and Eleana Edens, 305-334. Mahawa: Lawrence Erlbaum.

Hergüner, Gulten, and Nigel B.R. Reeves. 2000. Going against the national cultural grain: a longitudinal case study of organizational culture change in Turkish higher education. Total Quality Management 11(1):45-56.

Herkenhoff, Linda. 2004. Culturally tuned emotional intelligence: an effective change management tool? Strategic Change 13(2):73-81.

Hiller, Nathan J., David V. Day, and Robert J. Vance. 2006. Collective enactment of leadership roles and team effectiveness: a field study. The Leadership Quarterly 17(4):387-397.

Hillmann, Julia. 2020. Disciplines of organizational resilience: contributions, critiques, and future research avenues. Review of Managerial Science. https://doi.org/10.1007/s11846-020-00384-2.

Hillmann, Julia, and Edeltraud Guenther. 2020. Organizational resilience: a valuable construct for management research? International Journal of Management Reviews 23(1):7-44. https://doi.org/10.1111/ ijmr. 12239.

Hillmann, Julia, Stephanie Duchek, Julian Meyr, and Edeltraud Guenther. 2018. Educating future managers for developing resilient organizations: the role of scenario planning. Journal of Management Education 42(4):461-495.

Hofstede, Geert. 1980. Culture's consequences: Comparing values, behaviors, institutions and organizations across nations. Thousand Oaks: Sage Publications.

Hofstede, Geert. 1983. The cultural relativity of organizational practices and theories. Journal of International Business Studies 14(2):75-89.

Hofstede, Geert. 1993. Cultural constraints in management theories. Academy of Management Perspectives 7(1):81-94.

Hofstede, Geert. 2001. Culture's consequences: comparing values, behaviors, institutions and organizations across nations. Thousand Oaks: SAGE.

Hofstede, Geert. 2006. What did GLOBE really measure? Researchers' minds versus respondents' minds. Journal of International Business Studies 37(6):882-896.

Hofstede, Geert. 2011. Dimensionalizing cultures: the Hofstede model in context. Online Readings in Psychology and Culture 2(1): w/o page.

Hofstede, Geert, and Robert R. McCrae. 2004. Personality and culture revisited: linking traits and dimensions of culture. Cross-Cultural Research 38(1):52-88.

Hofstede, Geert, Gert Jan Hofstede, and Michael Minkov. 2010. Cultures and organizations: software for the mind, 3rd edn., : McGraw-Hill.

Horne, John F., and John E. Orr. 1998. Assessing behaviors that create resilient organizations. Employment Relations Today (Wiley) 24(4):29-39.

Hornsby, Jeffrey S., James M. Bloodgood, James Hayton, and Donald F. Kuratko. 2013. Network legitimacy diffusion: a model for corporate entrepreneurship. International Entrepreneurship and Management Journal 9(3):307-322.

House, Robert J., Paul J. Hanges, Mansan Javidan, Peter W. Dorfman, and Vipin Gupta. 2004. Culture, leadership, and organizations the GLOBE study of 62 societies. Thousand Oaks: SAGE.

Ishak, Andrew Waguih, and Elizabeth Ann Williams. 2018. A dynamic model of organizational resilience: adaptive and anchored approaches. Corporate Communications: An International Journal 23(2):180-196.

Ismail, Maimunah, and Hoo S. Lu. 2014. Cultural values and career goals of the millennial generation: an integrated conceptual framework. Journal of International Management Studies 9(1):38-49.

Issel, L.M., and Kusuma M. Narasimha. 2007. Creating complex health improvement programs as mindful organizations: from theory to action. Journal of health organization and management 21(2):166-183.

Jackson, Susan E., and Jane E. Dutton. 1988. Discerning threats and opportunities. Administrative Science Quarterly 33:370-387.

Jiao, Changquan, David A. Richards, and Rick D. Hackett. 2013. Organizational citizenship behavior and role breadth: a meta-analytic and cross-cultural analysis. Human Resource Management 52(5):697-714.

Johns, Gary. 2006. The essential impact of context on organizational behavior. Academy of management review 31(2):386-408.

Johns, Gary. 2018. Advances in the treatment of context in organizational research. Annual Review of Organizational Psychology and Organizational Behavior 5:21-46.

Kaiser, Henry F. 1974. An index of factorial simplicity. Psychometrika 39(1):31-36. 
Karam, Charlotte M., and David A. Ralston. 2016. A failure before analysis: the soup to nuts of preparing for multicountry analyses. Cross Cultural \& Strategic Management 23(4):590-612.

Kenessey, Zoltan. 1987. The primary, secondary, tertiary and quaternary sectors of the economy. Review of Income and Wealth 33(4):359-385.

King, Andrew. 1995. Avoiding ecological surprise: lessons from long-standing communities. Academy of Management review 20(4):961-985.

Kirkman, Bradley L., Kevin B. Lowe, and Cristina B. Gibson. 2006. A quarter century of culture's consequences. A review of empirical research incorporating Hofstede's cultural values framework. Journal of International Business Studies 37(3):285-320.

Kluckhohn, C. 1951. The study of culture. In The policy sciences, ed. D. Lerner, H.D. Lasswell. Stanford: Stanford University Press.

Kluckhohn, Florence R., and Fred L. Strodtbeck. 1961. Variations in value orientations. Oxford: Row, Peterson.

Lažnjak, Jasminka. 2011. Dimensions of national innovation culture in croatia: content validity of hofstede's dimensions. Drustvena istrazivanja 20(4):1015-1038.

Lengnick-Hall, Cynthia A., and T.E. Beck. 2005. Adaptive fit versus robust transformation: how organizations respond to environmental change. Journal of Management 31(5):738-757.

Lengnick-Hall, Cynthia A., T.E. Beck, and Mark L. Lengnick-Hall. 2011. Developing a capacity for organizational resilience through strategic human resource management. Human Resource Management Review 21(3):243-255.

Lester, Donald L., John A. Parnell, and Shawn Carraher. 2003. Organizational life cycle: a five-stage empirical scale. The International Journal of Organizational Analysis 11(4):339-354.

Limnios, Elena A.M., Tim Mazzarol, Anas Ghadouani, and Steven G.M. Schilizzi. 2014. The resilience architecture framework: four organizational archetypes. European Management Journal 32(1):104-116.

Linnenluecke, Martina K. 2017. Resilience in business and management research: a review of influential publications and a research agenda. International Journal of Management Reviews 19(1):4-30.

Little, Roderick J.A., and Donald B. Rubin. 2002. Statistical analysis with missing data: Wiley series in probability and statistics, 2nd edn., Hoboken: Wiley.

Livermore, Celia R., and Pierluigi Rippa. 2014. ERP implementation: a cross-cultural perspective. Journal of Global Information Technology Management 14(3):5-26.

Low Kim Cheng, Patrick. 2007. The cultural value of resilience: the Singapore case study. Cross Cultural Management: An International Journal 14(2):136-149.

Luczak, Cheryl, Sumaria Mohan-Neill, and Gerald Hills. 2010. National culture, market orientation and network-derived benefits: conceptual model for service SME's. Academy of Entrepreneurship Journal 16(2):1-21.

Luczak, Cheryl, Sumaria Mohan-Neill, and Gerald Hills. 2014. A quantitative study of business owners and perceived network benefits: Collectivist vs. individualist based cultures. Academy of Entrepreneurship Journal 20(2):1-19.

Lynch, Scott M. 2007. Introduction to applied Bayesian statistics and estimation for social scientists. New York: Springer.

Lytle, A.L., J.M. Brett, Z.I. Barsness, C.H. Tinsley, and M. Janssens. 1995. A paradigm for confirmatory cross-cultural research in organizational behavior. In Research in Organizational Behavior 17, ed. L.L. Cummings, B.M. Staw, 167-214. Greenwich: JAI Press.

MacKay, Brad, and Peter McKiernan. 2010. Creativity and dysfunction in strategic processes: the case of scenario planning. Futures 42(4):271-281.

MacNab, Brent, Richard Brislin, Reg Worthley, Bella L. Galperin, Steve Jenner, Terri R.Terri R. Lituchy, et al. 2007. Culture and ethics management. International Journal of Cross Cultural Management 7(1):5-28.

Mallak, Larry A. 1998. Measuring resilience in health care provider organizations. Health Manpower Management 24(4):148-152.

Mantere, Saku, Henri Schildt, and John A. Sillince. 2012. Reversal of strategic change. Academy of Management Journal 55(1):173-196.

Markus, Hazel R., and Shinobu Kitayama. 1991. Culture and the self: Implications for cognition, emotion, and motivation. Psychological Review 98(2):224-253.

Matveev, Alexei V., and Paul E. Nelson. 2004. Cross cultural communication competence and multicultural team performance. International Journal of Cross Cultural Management 4(2):253-270.

McCann, Joseph E., and John W. Selsky. 2012. Mastering turbulence: the essential capabilities of agile and resilient individuals, teams, and organizations, 1st edn., San Francisco: Jossey-Bass. 
McCann, Joseph, John Selsky, and James Lee. 2009. Building agility, resilience and performance in turbulent environments. People \& Strategy 32(3):44-51.

McManus, Sonia, Erica Seville, John Vargo, and David Brunsdon. 2008. Facilitated process for improving organizational resilience. Natural Hazards Review 9(2):81-90.

McSweeney, Brendan. 2002. Hofstede's model of national cultural differences and their consequences: a triumph of faith—a failure of analysis. Human Relations 55(1):89-118.

Merritt, Ashleigh. 2000. Culture in the cockpit: do Hofstede's dimensions replicate? Journal of CrossCultural Psychology 31(3):283-301.

Miller, C.C., and Laura B. Cardinal. 1994. Strategic planning and firm performance: a synthesis of more than two decades of research. Academy of Management Journal 37(6):1649-1665.

Miller, Danny, and Peter H. Friesen. 1984. A longitudinal study of the corporate life cycle. Management Science 30(10):1161-1183.

Morgan, Paul B.C., David Fletcher, and Mustafa Sarkar. 2013. Defining and characterizing team resilience in elite sport. Psychology of Sport and Exercise 14(4):549-559.

Newman, Karen L., and Stanley D. Nollen. 1996. Culture and congruence: the fit between management practices and national culture. Journal of International Business Studies 27(4):753-779.

Nicholls-Nixon, Charlene L. 2005. Rapid growth and high performance: the entrepreneur's "impossible dream?". Academy of Management Executive 19(1):77-89.

Ortiz-de-Mandojana, Natalia, and Pratima Bansal. 2016. The long-term benefits of organizational resilience through sustainable business practices. Strategic Management Journal 37(8):1615-1631.

Osborne, Jason. 2013. Six: dealing with missing or incomplete data: debunking the myth of emptiness. In Best practices in data cleaning: a complete guide to everything you need to do before and after collecting your data, ed. Jason Osborne, 105-138. Thousand Oaks: SAGE.

Pal, Rudrajeet, Håkan Torstensson, and Heikki Mattila. 2014. Antecedents of organizational resilience in economic crises-an empirical study of Swedish textile and clothing SMEs. International Journal of Production Economics 147:410-428.

Podsakoff, Philip M., Scott B. MacKenzie, Lee Jeong-Yeon, and Nathan P. Podsakoff. 2003. Common method biases in behavioral research: A critical review of the literature and recommended remedies. Journal of Applied Psychology 88(5):879-903.

Putnam, R. 1995. Tuning in, tuning out: the strange disap-pearance of social capital in america. Political Science and Politics 28(4):664-683.

Quinn, Robert E., and Kim Cameron. 1983. Organizational life cycles and shifting criteria of effectiveness: some preliminary evidence. Management Science 29(1):33-51.

Rerup, Claus. 2001. 'Houston we have a problem': anticipation and improvisation as sources of organizational resilience. Comportamento Organizacional E Gestao 7(1):27-44.

Rinne, Tiffany, G.D. Steel, and John Fairweather. 2012. Hofstede and Shane revisited: the role of power distance and individualism in national-level innovation success. Cross-Cultural Research 46(2):91-108.

Riolli, Laura, and Victor Savicki. 2003. Information system organizational resilience. Omega 31(3):227-233.

Ronen, Simcha, and Oded Shenkar. 2013. Mapping world cultures: cluster formation, sources and implications. Journal of International Business Studies 44(9):867-897.

Salanova, Marisa, Susana Llorens, Eva Cifre, and Isabel M. Martínez. 2012. We need a hero! Toward a validation of the healthy and resilient organization (HERO) model. Group \& Organization Management 37(6):785-822.

Schafer, Joseph L., and John W. Graham. 2002. Missing data: Our view of the state of the art. Psychological Methods 7(2):147-177.

Schein, Edgar H. 2001. The Impact of Transnational Institutions on Cultural Values and Vice Versa. Reflections: The SoL Journal 3(1):41-48.

Schmitz, Lena, and Wiebke Weber. 2014. Are Hofstede's dimensions valid? A test for measurement invariance of Uncertainty Avoidance. Interculture Journal 13(22):11-26.

Schwarzer, Ralf, and Lisa Marie Warner. 2013. Perceived Self-Efficacy and its Relationship to Resilience. In Resilience in Children, Adolescents, and Adults The Springer Series on Human Exceptionality., ed. S. Prince-Embury, D. Saklofske. New York: Springer.

Scott, W. Richard, and Gerald. F. Davis. 2014. Organizations and Organizing: Rational, Natural, and Open Systems Perspectives. Harlow: Pearson Education.

Shane, Scott. 1994. The effect of national culture on the choice between licensing and direct foreign investment. Strategic Management Journal 15(8):627-642.

Sharma, Shikha, and Sanjeev Kumar Sharma. 2016. Team resilience: scale development and validation. Vision 20(1):37-53. 
Sheffi, Yosef. 2005. The resilient enterprise: overcoming vulnerability for competitive advantage. Cambridge: MIT Press.

Shin, Jiseon, M.S. Taylor, and Myeong-Gu Seo. 2012. Resources for Change: the Relationships of Organizational Inducements and Psychological Resilience to Employees' Attitudes and Behaviors toward Organizational Change. Academy of Management Journal 55(3):727-748.

Somers, Scott. 2009. Measuring resilience potential: an adaptive strategy for organizational crisis planning. Journal of Contingencies \& Crisis Management 17(1):12-23.

Søndergaard, Mikael. 1994. Research note: Hofstede's consequencies: a study of reviews, citations and replications. Organization Studies 15(3):447-456.

Starr, Randy, Jim Newfrock, and Michael Delurey. 2003. Enterprise resilience: managing risk in the networked economy. Strategy and Business 30 (1):1-150.

Statistics Canada. 2012. French and the Francophonie in Canada: Language, 2011 Census of Population

Steinhardt, Mary, and Christyn Dolbier. 2008. Evaluation of a resilience intervention to enhance coping strategies and protective factors and decrease symptomatology. Journal of American College Health 56(4):445-453.

Stephenson, Amy. 2010. Benchmarking the Resilience of Organisations. Dissertation, Civil and Natural Resources Engineering Department, University of Canterbury.

Stolowy, Hervé. 2017. Letter from the editor: why are papers desk rejected at European Accounting Review? European Accounting Review. https://doi.org/10.1080/09638180.2017.1347360.

Sulphey, M.M. 2020. A study on the effect of long-term orientation and risk propensity on resilience. International Journal of Sociology and Social Policy 40(11/12):1585-1610. https://doi.org/10.1108/ IJSSP-09-2019-0192.

Sutcliffe, Kathleen M., and Timothy J. Vogus. 2003. Organizing for resilience. In Positive organizational scholarship: Foundations of a new discipline, 1st edn., ed. Kim S. Cameron, Jane E. Dutton, and Robert E. Quinn. San Francisco: Berrett-Koehler.

Taras, Vas, Bradley L. Kirkman, and Piers Steel. 2010. Examining the impact of culture's consequences: a three-decade, multilevel, meta-analytic review of Hofstede's cultural value dimensions. Journal of Applied Psychology 95(3):1035-1057.

Taras, Vas, Piers Steel, and Bradley L. Kirkman. 2012. Improving national cultural indices using a longitudinal meta-analysis of Hofstede's dimensions. Journal of World Business 47(3):329-341.

Tasic, Justyna, Fredy Tantri, and Sulfikar Amir. 2019. Modelling multilevel interdependencies for resilience in complex organisation. Complexity. https://doi.org/10.1155/2019/3946356.

Tata, Jasmine, and Sameer Prasad. 2015. National cultural values, sustainability beliefs, and organizational initiatives. Cross Cultural Management: An International Journal 22(2):278-296.

Tavanti, Marco. 2012. The cultural dimensions of Italian leadership: Power distance, uncertainty avoidance and masculinity from an American perspective. Leadership 8(3):287-301.

Triandis, Harry Charalambos. 2004. Culture and social behavior. Boston: McGraw-Hill.

Tsui, Anne S., Sushil S. Nifadkar, and Amy Yi Ou. 2007. Cross-national, cross-cultural organizational behavior research: advances, gaps, and recommendations. Journal of management 33(3):426-478.

Upadhyaya, Shikha, and Terri L. Rittenburg. 2015. Cultural influences on experiences of and responses to consumer vulnerability. In Proceedings of the 40th Annual Macromarketing Conference, ed. Raymond Benton, Clifford Shultz, and Olga Kravets, 59-70.

Välikangas, Liisa. 2007. Rigidity, exploratory patience, and the ecological resilience of organizations. Scandinavian Journal of Management 23(2):206-213.

Vogus, Timothy J., and Kathleen M. Sutcliffe. 2007. Organizational resilience: towards a theory and research agenda. Montreal: Que.

Walumbwa, Fred Ochieng, and John J. Lawler. 2003. Building effective organizations: transformational leadership, collectivist orientation, work-related attitudes and withdrawal behaviours in three emerging economies. International Journal of Human Resource Management 14(7):1083-1101.

Weick, K.E. 1969. The social psychology of organizing. Reading: Addison-Wesley.

Weick, Karl E. 1993. The collapse of Sensemaking in organizations: the Mann gulch disaster. Administrative Science Quarterly 38(4):628-652.

Weick, Karl E., and Kathleen M. Sutcliffe. 2007. Managing the unexpected: assuring high performance in an age of complexity, 1st edn., San Fransisco: Jossey-Bass.

West, Bradley J., Jaime L. Patera, and Melissa K. Carsten. 2009. Team level positivity: investigating positive psychological capacities and team level outcomes. Journal of Organizational Behavior 30(2):249-267.

Whiteman, Gail, and William H. Cooper. 2011. Ecological sensemaking. Academy of Management Journal 54(5):889-911. 
Williams, Trenton A., and Dean A. Shepherd. 2016. Building resilience or providing sustenance: different paths of emergent ventures in the aftermath of the Haiti earthquake. Academy of Management Journal 59(6):2069-2102.

Williams, Trenton A., Daniel A. Gruber, Kathleen M. Sutcliffe, Dean A. Shepherd, and Eric Yanfei Zhao. 2017. Organizational response to adversity: Fusing crisis management and resilience research streams. Academy of Management Annals 11(2):733-769.

Wright, Christopher, Chung-Sok Suh and Christopher Leggett. 2009. If at first you don't succeed: globalized production and organizational learning at the Hyundai Motor Company. Asia Pacific Business Review 15(2):163-180.

Yong, An G., and Sean Pearce. 2013. A beginner's guide to factor analysis: focusing on exploratory factor analysis. Tutorials in Quantitative Methods for Psychology 9(2):79-94.

Young, Rebekah. 2012. Don't know responses in survey research. Dissertation, Department of Sociology. The Pennsylvania State University.

Zhou, Zhongyun, Xiao-Ling Jin, Yulin Fang, and Doug Vogel. 2015. Toward a theory of perceived benefits, affective commitment, and continuance intention in social virtual worlds: cultural values (indulgence and individualism) matter. European Journal of Information Systems 24(3):247-261.

Zimmerman, Ann S. 2008. New knowledge from old data: The role of standards in the sharing and reuse of ecological data. Science, technology, \& human values 33(5):631-652. 